(C) 2019. This manuscript version is made available under the CCBY-NC-ND 4.o license http://creativecommons.org/licenses/by-nc-nd/4.o/ 


\section{Accepted Manuscript}

Evaluation of the electrochemical performance of electrospun transition metal oxidebased electrode nanomaterials for water CDI applications

Saveria Santangelo, Fabiola Pantò, Claudia Triolo, Sara Stelitano, Patrizia Frontera, Francisco Fernández-Carretero, Inés Rincon, Patxi Azpiroz, Alberto García-Luis, Yolanda Belaustegui

PII: S0013-4686(19)30761-3

DOI: https://doi.org/10.1016/j.electacta.2019.04.075

Reference: $\quad$ EA 34023

To appear in: Electrochimica Acta

Received Date: 23 December 2018

Revised Date: 5 April 2019

Accepted Date: 12 April 2019

Please cite this article as: S. Santangelo, F. Pantò, C. Triolo, S. Stelitano, P. Frontera, F. FernándezCarretero, Iné. Rincon, P. Azpiroz, A. García-Luis, Y. Belaustegui, Evaluation of the electrochemical performance of electrospun transition metal oxide-based electrode nanomaterials for water CDI applications, Electrochimica Acta (2019), doi: https://doi.org/10.1016/j.electacta.2019.04.075.

This is a PDF file of an unedited manuscript that has been accepted for publication. As a service to our customers we are providing this early version of the manuscript. The manuscript will undergo copyediting, typesetting, and review of the resulting proof before it is published in its final form. Please note that during the production process errors may be discovered which could affect the content, and all legal disclaimers that apply to the journal pertain. 


\title{
Evaluation of the electrochemical performance of electrospun transition metal oxide-based electrode nanomaterials for water CDI applications
}

Saveria Santangelo ${ }^{1, *}$, Fabiola Pantò $^{2}$, Claudia Triolo ${ }^{3}$, Sara Stelitano ${ }^{4}$, Patrizia Frontera ${ }^{1}$, Francisco Fernández-Carretero ${ }^{5}$, Inés Rincon ${ }^{5}$, Patxi Azpiroz ${ }^{5}$, Alberto García-Luis ${ }^{5}$, Yolanda Belaustegui ${ }^{5}$

1 Dipartimento di Ingegneria Civile, dell'Energia, dell'Ambiente e dei Materiali (DICEAM), Università “Mediterranea”, 89122 Reggio Calabria, Italy

${ }^{2}$ Istituto di Tecnologie Avanzate per l'Energia (ITAE) del Consiglio Nazionale delle ricerche (CNR), 98126 Messina, Italy

${ }^{3}$ Università di Messina, Dipartimento di Scienze Matematiche e Informatiche, Scienze Fisiche e Scienze della Terra (MIFT), 98166 Messina, Italy.

${ }_{5}^{4}$ Dipartimento di Fisica (DF), Università della Calabria, 87036 Arcavacata di Rende, Italy

${ }^{5}$ Tecnalia Research \& Innovation, Materials for Energy and Environment Area, E-48160 DerioBizkaia, Spain

\begin{abstract}
Composite fibrous materials based on (graphene-enriched) nitrogen-doped carbon/transition metal oxides were produced by electrospinning and their physicochemical properties were thoroughly investigated by a combination of characterisation techniques. The electrochemical behaviour of the electrodes prepared with them was evaluated in view of their use in the capacitive deionisation of saline water. The morphology of the materials reminded of usnea florida lichens, wheat ears, sea sponges and noodles and depended on the transition metal ( $\mathrm{Mn}, \mathrm{Fe}$, Ti or $\mathrm{Zn}$ ). The morphology and the relative amount (14.1-22.2 $\mathrm{wt} \%)$ of the surface nitrogen and carbon-bonded oxygen functional species, beneficial to wettability and involving pseudocapacitive processes, had strong impact on the specific capacitance $\left(43.7-67.4 \mathrm{~F} \mathrm{~g}^{-1}\right.$, at $5 \mathrm{~m} \mathrm{~V} \mathrm{~s}^{-1}$ scan rate), whereas also the specific micropore volume $\left(0.4-5.6 \mathrm{~mm}^{3} \mathrm{~g}^{-1}\right)$ affected the effective areal capacitance of the electrodes $\left(1.2-6.0 \mathrm{~F} \mathrm{~m}^{-2}\right.$, at $\left.5 \mathrm{mV} \mathrm{s}^{-1}\right)$. Ion storage in the composite materials occurred via a mixed capacitive/pseudocapacitive process. Hence, increasing the content of the oxide (from 24.6 to 56.7 $\mathrm{wt} \%$ ), thanks to the fast-reversible redox reactions at or near surface it involves, partly compensated for the growing hindrance to diffusion encountered by the ions (hampered electrostatic adsorption) as the scan rate increased from 5 to $100 \mathrm{mV} \mathrm{s}^{-1}$.
\end{abstract}

Keywords: Electrospinning, Capacitive de-ionization, Transition Metal Oxides, Composite fibres, Surface functional species.

\footnotetext{
* Corresponding author

Tel.: +39.0965.1692305. Fax.: +39.0965.1692201. E-mail address: saveria.santangelo@ unirc.it (Prof. Saveria Santangelo)
} 


\section{Introduction}

The increase of world population reflects on a growing demand for fresh water, further boosted by the increasing level of environmental contamination of the commonly exploited aquifer sources. This situation has encouraged the development of the water desalination technologies, and particularly of those addressed to cost-effectiveness and energy-efficiency. Among them, the capacitive de-ionization (CDI) is one of the most attractive for its simplicity and eco-friendliness.

CDI, also known as electro-sorptive desalination, is based on the formation of an electrical double layer (EDL) between the parallel electrodes, forming the CDI cell $[1,2,3,4]$ upon application of a voltage between them. In the presence of the EDL, the ions, present in the salty water inlet into the cell, are reversibly stored onto the porous surface of the charged electrode by electric potentialinduced adsorption and fresh water goes out from the cell. During this process, no secondary contaminant is released. Once their surface is saturated with salt ions, the electrodes can be regenerated by reversing/shorting the cell voltage. This causes the stored ions to be desorbed and to be released into a wastewater solution.

Low operating voltage of CDI $(0.8-1.2 \mathrm{~V})$ can be of great help in remote areas. In addition, energy required to desalinate one cubic meter of brackish waters is lower than for reverse osmosis (only 100 against $200 \mathrm{Wh}$ ) [3].

The capacitance of the porous electrode material and, hence, its desalination performance depends on its specific surface area, as well as on its ionic conduction properties. A great variety of carbon-based electrode materials, including carbon aerogel [5,6], activated carbons [7], carbon nanotubes [8,9], electrospun carbon nanofibers [10,11,12,13], graphene [14] and graphene-enriched carbonaceous nanostructures [13,15], have been developed in order to improve the CDI performance. Very recently, it has been demonstrated that electrospun carbon fibres doped with very high nitrogen concentrations (around $20 \mathrm{wt} \%$ ) are able to remove a relevant amount of $\mathrm{NaCl}$ $\left(17.0 \mathrm{mg} \mathrm{g}^{-1}\right.$ ) from a salty solution with an initial concentration of $585 \mathrm{mg} \mathrm{L}^{-1}$, and that the electrosorption capacity outstandingly increases (up to $27.6 \mathrm{mg} \mathrm{g}^{-1}$ ) if the $\mathrm{N}$-doped fibres are enriched with graphene [13].

However, generally speaking, porous carbon-based electrodes, which store ions through electrostatic interactions with their surface, have a limited salt adsorption capacity. Therefore, their porosity, hydrophilicity and capacitance properties need to be improved. To increase the deionization capacity of electrodes for salt ion removal, a variety of redox-active materials based on transition metal oxides (TMOs) has been also evaluated. Among them, carbon aerogels doped with manganese or iron oxides prepared by the resorcinol-formaldehyde method [16], three-dimensional graphene/metal oxide $\left(\mathrm{TiO}_{2}, \mathrm{CeO}_{2} \mathrm{Fe}_{2} \mathrm{O}_{3}\right.$ and $\left.\mathrm{Mn}_{3} \mathrm{O}_{4}\right)$ hybrids [3] and $\mathrm{RuO}_{2}$-activated carbon composite electrodes prepared via electrodeposition [17]. TMOs, generally featured by high theoretical specific capacities, environmental friendliness, low cost and high abundance on earth, have received noticeable consideration as active components also in rechargeable batteries [18,19,20,21,22,23,24], supercapacitor [25,26,27,28,29] and energy storage applications [30]. TMOs, able to store ions through a Faradaic process involving reversible redox reactions at or near surface, endow hybrid carbon/TMOs nanomaterials with enhanced capacitance and, hence, significantly improved adsorption capacity.

Several different methods are successfully utilised to produce the active electrode materials for CDI cells. Electrospinning (ES), a very simple, scalable and cost-effective technique, allows successfully producing one-dimensional nanostructures featured by hierarchical porosity (intertwined micro-, meso-, and macro-pores) and large specific surface area [13,19,20,31,32,33]. ES is particularly suitable for the manufacturing of fibrous electrode materials on an industrial scale since the production process proceeds through two well distinct steps (namely, fibrous film deposition and subsequent thermal treatment), with no need of interruptions.

This paper deals with synthesis of electrospun TMO-based fibres to be used as active hybrid materials for the preparation of electrodes for CDI cells. The physicochemical properties of the materials produced by ES were thoroughly investigated, and the electrochemical behaviour of the 
electrodes prepared with them was evaluated. Interesting correlations emerged from the present study, which can provide guidelines for the active CDI-electrode material designing and utilisation condition selection.

\section{Experimental}

\subsection{Materials}

Sigma Aldrich supplied all reactants needed for the active material preparation, namely iron (II) acetate $\left(\left(\mathrm{CH}_{3} \mathrm{COO}\right)_{2} \mathrm{Fe}\right.$, purity: 95\%, molecular weight: $245.09 \mathrm{~g} \mathrm{~mol}^{-1}$, CAS No. 6156-78-1), manganese (II) acetate tetrahydrate $\left(\left(\mathrm{CH}_{3} \mathrm{COO}\right)_{2} \mathrm{Mn} \cdot 4 \mathrm{H}_{2} \mathrm{O}\right.$, purity: $99.99 \%$ trace metals basis, molecular weight: $245.09 \mathrm{~g} \mathrm{~mol}^{-1}$, CAS No. 6156-78-1), N,N-dimethylformamide $\left(\mathrm{HCON}\left(\mathrm{CH}_{3}\right)_{2}\right.$, anhydrous: $99.8 \%$, CAS No. 68-12-2), polyacrylonitrile $\left(\left(\mathrm{C}_{3} \mathrm{H}_{3} \mathrm{~N}\right)_{\mathrm{n}}\right.$, purity: $99.9 \%$, average molecular weight: $150000 \mathrm{~g} \mathrm{~mol}^{-1}$, CAS No. 25014-41-9) tetraethyl orthosilicate $\left(\mathrm{Si}\left(\mathrm{OC}_{2} \mathrm{H}_{5}\right)_{4}\right.$, purity: 98\%, molecular weight: $208.33 \mathrm{~g} \mathrm{~mol}^{-1}$, CAS No. 78-10-4), titanium (IV) isopropoxide, ( $\mathrm{Ti}\left[\mathrm{OCH}\left(\mathrm{CH}_{3}\right)_{2}\right]_{4} \cdot 4 \mathrm{H}_{2} \mathrm{O}$, purity: $97 \%$, molecular weight: $284.22 \mathrm{~g} \mathrm{~mol}^{-1}$, CAS No. 546-68-9) and zinc (II) acetate dihydrate $\left(\left(\mathrm{CH}_{3} \mathrm{COO}\right)_{2} \mathrm{Zn} \cdot 2 \mathrm{H}_{2} \mathrm{O}\right.$, purity: $99.99 \%$ trace metals basis, molecular weight: $219.51 \mathrm{~g} \mathrm{~mol}^{-1}$, CAS No. 5970-45-6), as well graphite powder (lateral size: < $20 \mu \mathrm{m}$ ) for graphene oxide preparation. All materials were utilised without any further purification.

Polyacrylonitrile (PAN) and $N, N$-dimethylformamide (DMF) acted as polymer and solvent, respectively. Iron (II) acetate $\left(\mathrm{FeAc}_{2}\right)$, manganese (II) acetate tetrahydrate $\left(\mathrm{MnAc}_{2}\right)$, tetraethyl orthosilicate (TEOS), titanium (IV) isopropoxide (TIP) and zinc (II) acetate dihydrate ( $\left.\mathrm{ZnAc}_{2}\right)$ were utilised as iron, manganese, silicon, titanium and zinc sources, respectively.

\subsection{Graphene oxide}

Graphene oxide (GO) to be used as an additive for the generation of graphene-enriched fibres was obtained from as-purchased graphite powder via a modified Hummers method [34], as reported in detail elsewhere [13]. Briefly, $\mathrm{K}_{2} \mathrm{~S}_{2} \mathrm{O}_{8}$ and $\mathrm{P}_{2} \mathrm{O}_{5}$ were added to a suspension of graphite powder in concentrated $\mathrm{H}_{2} \mathrm{SO}_{4}$ for pre-oxidation and after heating, the solid, recovered by centrifugation, was repeatedly washed with water and dried. Subsequently, pre-oxidized graphite was added to concentrate $\mathrm{H}_{2} \mathrm{SO}_{4}$. After stirring in an ice bath, $\mathrm{NaNO}_{3}$ and $\mathrm{KMnO}_{4}$ were added. The solution obtained under vigorous stirring at $10^{\circ} \mathrm{C}$ was kept for 5 days at room temperature (RT). After water addition, the suspension was heated and $30 \mathrm{wt} \% \mathrm{H}_{2} \mathrm{O}_{2}$ was added. Finally, after filtering and washing with $2 \mathrm{M} \mathrm{HCl}$ solution, the suspension was repeatedly washed with water and dried. The obtainment of GO was ascertained by carrying out Raman scattering and x-ray diffraction measurements, as previously reported [13].

\subsection{Preparation of the electrospun fibrous nanomaterials}

The experimental procedure followed to synthesise the fibrous nanomaterials for the electrode preparation was described in detail in previous papers $[13,19,20]$. Briefly, the spinnable solution with the desired composition (Table 1) was first prepared by sol-gel method. For this purpose, a fixed amount of PAN (6.5 wt\%) was dissolved in DMF and the resulting solution was stirred until it became clear. Then, precursor(s) and GO additive (if any) were added and the solution obtained after further magnetic stirring was electrospun using a $\mathrm{CH}-01$ Electro-spinner 2.0 (Linari Engineering s.r.l.). The spinning process was carried out at $20 \pm 1^{\circ} \mathrm{C}$ temperature and $40 \%$ relative air humidity. A $20 \mathrm{~mL}$ syringe equipped with a $40 \mathrm{~mm}$ long $0.8 \mathrm{~mm}$ gauge stainless steel needle was utilised. Solution was fed at $23.5 \mu \mathrm{L} \mathrm{min}{ }^{-1}$. A $15 \mathrm{kV}$ voltage was applied over a collection distance of $11 \mathrm{~cm}$.

After drying over night at RT for residual solvent removal, the as-spun membrane was peeledoff from the collector and was thermally treated to generate the desired oxide-, carbon- or composite carbon/oxide fibres. The oxide fibres (OFs) were obtained by complete elimination of the 
organic constituents through a single oxidative process in static air (calcination). The remaining samples, including both graphene-enriched nitrogen-doped carbon fibres (GNCFs) and composite NC/oxide or GNC/oxide fibres (NC/OFs and GNC/OFs, respectively), were produced via a twostep process, involving an oxidative treatment (polymer stabilisation) in static air, followed by an annealing process (carbonisation) operated, under inert atmosphere, at relatively low temperature $\left(500^{\circ} \mathrm{C}\right)$. As previously demonstrated $[13,20]$, the choice of a polymer (PAN) with a high N-content (26.4 wt\%), if coupled with proper heat treatment conditions, allowed obtaining electrospun carbon (or carbon-based composite) fibres with high N-doping levels, which is believed to be beneficial for the fibre wettability $[4,13,14,35,36,37]$.

Table 1 reports temperatures and durations of the thermal treatments, which were operated increasing temperature at $5^{\circ} \mathrm{C} \mathrm{min}^{-1}$ rate and were followed by uncontrolled cooling down to RT.

\subsection{Physicochemical characterisation of the electrospun fibrous nanomaterials}

After thermal processing, the produced nanomaterials were analysed by means of a combination of complementary techniques. A Phenom Pro-X scanning electron microscope equipped with an energy-dispersive X-ray (EDX) spectrometer was utilised to investigate their texture and morphology by scanning electron microscopy (SEM). Automated accurate measurements of the diameters of the fibres from their SEM images were carried out by the use of Fibermetric software. The results obtained are reported in Table 2. An ASAP 2010 Micromeritics instrument was utilised to determine the specific surface area of the samples via the BrunauerEmmett-Teller (BET) method. Measurements were carried out at $-196{ }^{\circ} \mathrm{C}$, after prolonged sample degassing at $150{ }^{\circ} \mathrm{C}$ in vacuum. From the recorded $\mathrm{N}_{2}$ adsorption-desorption isotherms, the pore size distribution was inferred via the Barrett-Joyner-Halenda $(\mathrm{BJH})$ approach and the specific micro-pore volume was calculated by means of the $t$-plot method. The results obtained are reported in Table 2.

The crystalline phases of the oxides were identified by x-ray diffraction (XRD) and microRaman spectroscopy (MRS). They are reported in Table 2. A Bruker D2 Phaser diffractometer, equipped with a $\mathrm{Ni} \beta$-filtered $\mathrm{Cu}-\mathrm{K}_{\alpha}$ radiation source, was utilised to record XRD patterns, whereas JCPDS database of reference compounds allowed for the diffraction-peak identification. A NTMDT NTEGRA - Spectra SPM spectrometer, equipped with MS3504i $350 \mathrm{~mm}$ monochromator and ANDOR Idus CCD, was utilised to measure Raman scattering excited by a solid-state laser operating at $2.33 \mathrm{eV}$. The scattered light from the sample was collected by a Mitutoyo high numerical aperture 100X objective. The use of a very low laser power $(250 \mu \mathrm{W}$ at the sample surface) prevented local heating of the samples and annealing effects.

Surface composition of the fibres and chemical environment of the component species were investigated by x-ray photoelectron spectroscopy (XPS). A M-Probe-SSI instrument, equipped with a monochromatic $\mathrm{Al} \mathrm{K}_{\alpha}$ source $(1486.6 \mathrm{eV})$, providing a resolution for $0.74 \mathrm{eV}$ was used. The results obtained are reported in Table 3.

Further details on the instrumentation utilised and experimental data processing can be found elsewhere $[13,19,20]$.

\subsection{Preparation of the working electrodes based on the electrospun fibrous nanomaterials}

The produced OFs, GNCFs, NC/OFs and GNC/OFs were utilised to prepare the working electrodes via the procedure described in detail below. In particular, as reported in Table 4, OFs and GNCFs were utilised to prepare physical mixtures, since their electrochemical properties, as active materials, were expected to be equivalent to that of the corresponding composite GNC/OFs, particularly at lower rates $[20,38]$. In addition, working electrodes based on the composite NC/OFs and GNC/OFs were prepared.

Electrodes were prepared by following the procedure schematically depicted in Fig. S1. To generate a slurry, a binder was added to the as-produced active nanomaterial (reference GNCFs, $\mathrm{NC} / \mathrm{OFs}$ or $\mathrm{GNC} / \mathrm{OFs}$ ) or to a physical mixture of GNCFs and $\mathrm{OFs}$, and the resulting material was 
dispersed in a solvent. Polyvinylalcohol $\left(\left(\mathrm{C}_{2} \mathrm{H}_{4} \mathrm{O}\right)_{\mathrm{x}}\right.$, PVA, Tecnalia) and ethanol $\left(\mathrm{C}_{2} \mathrm{H}_{5} \mathrm{OH}\right)$ were utilised as a binder and a solvent, respectively. The so-composed mixture was stirred for at least $8 \mathrm{~h}$ until obtaining the slurry.

The slurry was cast onto a graphite sheet (Graftech International), which acted as current collector, and dried in a $60^{\circ} \mathrm{C}$ oven overnight to remove the organic solvent and to form a planar electrode, composed by $90 \mathrm{wt} \%$ of as-produced electrospun active material and $10 \mathrm{wt} \%$ of PVA. Codes of the working electrodes and the nanomaterials utilised for their preparation are reported in Table 4. For the electrochemical measurements, electrodes with $2 \mathrm{~cm}^{2}$ area were utilised.

\subsection{Electrochemical three-cell measurements}

The electrochemical performance of the electrodes and the electrical double layer formation were evaluated by cyclic voltammetry (CV) and electrochemical impedance spectroscopy (EIS). CV measurements were done with a conventional three-electrode system, using a computercontrolled potentiostat/galvanostat (AUTOLAB PGSTAT302N, Metrohm) at RT. The working electrode $\left(2 \mathrm{~cm}^{2}\right.$ area) was prepared by using the as-produced electrospun active nanomaterial, as above described; graphite and a standard $\mathrm{Ag} / \mathrm{AgCl}$ electrode acted as the counter electrode and the reference electrode, respectively. For further details, see ref. [13].

$\mathrm{CV}$ measurements were performed with sweep rates of $5-100 \mathrm{mV} \mathrm{s}^{-1}$ in the potential range from -1 to $0.5 \mathrm{~V}$ in $0.1 \mathrm{~mol} \mathrm{~L}{ }^{-1} \mathrm{NaCl}$ solution. The values for specific capacitance of the CDI electrode material were calculated from the current-voltage curves according to the following equation:

$C s=\frac{1}{v m} \int \frac{I}{V} d V$

where $C_{S}\left(\mathrm{Fg}^{-1}\right)$ is the specific capacitance, $I(\mathrm{~A})$ is the response current, $V(\mathrm{~V})$ is the potential, $v(\mathrm{~V}$ $\left.\mathrm{s}^{-1}\right)$ is the potential scan rate and $m(\mathrm{~g})$ is the mass of the electro-active materials in the electrodes.

EIS analysis was conducted to determinate the internal resistance of the electrodes. The measurements were performed with AUTOLAB PGSTAT302N using the three compartment cell. The amplitude of the alternating voltage was $0.01 \mathrm{~V}$ around the equilibrium potential $(0 \mathrm{~V})$ and the data were collected in the frequency range from $10000 \mathrm{~Hz}$ to $0.1 \mathrm{~Hz}$.

\section{Results and discussion}

\subsection{Physicochemical properties of the fibrous electrode nanomaterials}

3.1.1 Morphological and textural properties. Samples obtained by through a single-step thermal treatment (OFs) were in the form of powders, whereas paper-like membranes, consisting of GNCFs, $\mathrm{NC} / \mathrm{OFs}$ or GNC/OFs, were generally obtained via the two-step process (Fig. S2). The morphology of the OFs had been already described in detail in a previous work [19]. Briefly, pure iron oxide

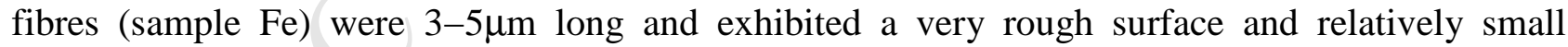
average diameter (Table 2), whereas Si-doped iron oxide fibres (sample FeSi) were shorter, smoother and thicker. In the case of the GNCFs (sample PG), as had been already pointed out [13], thermally reduced graphene oxide (TRGO) sheets were dispersed throughout the paper-like membrane, which was made fragile by the short length of the fibres due to the jet fragmentation induced by the exfoliation of GO sheets during the electrospinning process [13].

Figure 1 summarises the results of SEM analysis on the remaining samples. The composite NC/OFs and GNC/OFs exhibited very different and peculiar morphologies, which clearly depended on the oxide precursor, while the addition of GO to the spinnable solution seemed not to be influential. In particular, samples PMnG and PMn produced by the use of $\mathrm{MnAc}_{2}$ reminded of "usnea florida lichen" (Fig. 1a) and were featured by large oxide agglomerates. The use of $\mathrm{FeAc}_{2}$ (samples PFeG and PFe) gave rise to a "wheat ear-like" morphology (Fig. 1b), whereas sample PTi obtained from TIP exhibited a "sea sponge-like" morphology (Fig. 1c) with reduced formation of 
fibres. Finally, a "nooddle-like" morphology (Fig. 1d) was obtained by utilising $\mathrm{ZnAc}_{2}$ (sample PZn).

In agreement with previously reported results [13,20], for fixed oxide-precursor load, the addition of GO to the spinnable solution resulted in slightly thinner fibres as an effect of the GO polarity (Table 2), whereas, for a given oxide-precursor, the average fibre diameter increased with the oxide-precursor load.

Finally, the results of EDX analysis (Fig. S3) proven that the NC/OFs and GNC/OFs were nitrogen-doped (like the previously studied GNCFs [13]) and, regardless of the selected oxideprecursor and of the GO addition, the dispersion of carbon, oxygen, nitrogen and transition metal ( $\mathrm{TM}=\mathrm{Mn}, \mathrm{Fe}, \mathrm{Ti}$ or $\mathrm{Zn}$ ) within the fibrous nanomaterials was spatially uniform, as evidenced by the elemental mapping (Figs. 1i).

Table 2 reports the specific surface area $\left(S_{\mathrm{BET}}\right)$, specific micro-pore volume $\left(V_{\mathrm{MP}}\right)$, and average pore size $\left(d_{\mathrm{P}}\right)$ of the investigated GNCFs, NC/OFs and GNC/OFs. Owing to the low carbonisation temperature selected [13], the electrospun nanomaterials were generally featured by moderate $S_{\mathrm{BET}}$ values $\left(11-42 \mathrm{~m}^{2} \mathrm{~g}^{-1}\right)$.

Figures $2 \mathrm{a}-\mathrm{f}$ show the $\mathrm{N}_{2}$ adsorption/desorption isotherms of the investigated electrospun fibrous nanomaterials; the corresponding figure insets display the related pore size distributions. In the case of NC/OFs, the samples (PMn, PFe and PZn) showed an isotherm of type II according to BDDT classification [39], which pointed out the presence of micropores. In the case of the GNCFs (sample PG), as had been previously reported [13], the isotherm exhibited a typical type IV behaviour, with the presence of a steep slope at higher relative pressures. This finding indicated the occurrence of mesoporosity and macroporosity [40]. The same occurred for the GNC/OFs (samples $\mathrm{PMnG}$ and $\mathrm{PFeG}$ ).

Samples PG, PMnG and PFeG exhibited larger $S_{\mathrm{BET}}$ and $V_{\mathrm{MP}}$ with respect to $\mathrm{PMn}, \mathrm{PFe}$ and $\mathrm{PZn}$ (Table 2). By comparing the pore size distribution of the samples (insets of Figs. 2a-f), a (more or less marked) "spike" at 80-90 nm came into view in the pore size distributions of all the samples. It was previously detected also in N-doped C fibres (sample P) [13] and signalled the presence of macropores $(>50 \mathrm{~nm})$ peculiar to the electrospun carbonaceous matrix. GNC/OFs comprised a large fraction of mesopores $(2-50 \mathrm{~nm})$ and macropores, which is believed to be an optimal situation for electro-sorption in CDI process [2,4], since micropores $(<2 \mathrm{~nm})$ contribute to enhance the $S_{\mathrm{BET}}$ of the electrodes, but being hardly accessible for the ions, actually result in smaller CDI-active $S_{\mathrm{BET}}$ [41].

3.1.2 Crystalline phase of the oxide and graphitisation degree of the carbon component of the fibres. Figures 3 and 4 show the results of the XRD and MRS analyses carried out on the electrospun fibrous nanomaterials to identify the crystalline phase of the oxides formed upon thermal treatment and to assess the graphitisation degree of the carbon component in the GNCFs, GNC/OFs and NC/OFs. Only the signals from the oxide were generally visible in the XRD patterns of the carbon containing fibres (patterns c-f in Fig. 3), while the Raman fingerprint of their amorphous carbon component dominated their micro-Raman spectra (spectra c-f in Fig. 4 and Fig. $4 \mathrm{~b}$ ). The very broad and intense D- and G-bands arise from the $A_{1 \mathrm{~g}}$ breathing modes of the $\mathrm{C}$ atoms organised in hexagonal rings and the $E_{2 \mathrm{~g}}$ in-plane stretching of all the pairs of $\mathrm{C}$ atoms, respectively [42]. Since the former, activated by the presence of $\mathrm{Cs} p^{2}$ defects and heteroatoms in the graphitic lattice, intensifies relative to the latter with the increase of structural disorder [42], the G/D intensity ratio $\left(I_{\mathrm{G}} / I_{\mathrm{D}}\right)$ is commonly regarded as a graphitisation index, with $I_{\mathrm{G}} / I_{\mathrm{D}}>1$ for well-graphitised carbons $[13,20,43]$. In the present case, the $I_{\mathrm{G}} / I_{\mathrm{D}}$ ratio never exceeded 1 , as expected [44]. In fact, at low carbonisation temperature, the entanglement of PAN molecules within the electrospun fibres limits to larger extent the crystal development, leading to lower graphitisation degrees [44]. Besides, higher $\mathrm{N}$-doping levels of the fibres were achieved [45]. AS known [4,13,14,35,36,37], they are beneficial for their wettability but result in enhanced structural disorder of their carbon component. 
As concerns the OFs (obtained via a single-step heat process), in agreement with previously reported results [19], the XRD analysis revealed that rhombohedral hematite $\left(\alpha-\mathrm{Fe}_{2} \mathrm{O}_{3}\right.$, JCPDS card No. 33-0664) was the only crystalline phase formed in sample Fe (pattern a in Fig. 3), whereas two phases were detected in sample FeSi (pattern b in Fig. 3), namely maghemite $\left(\gamma-\mathrm{Fe}_{2} \mathrm{O}_{3}\right.$, JCPDS card No. 39-1346) and hematite, as the dominant and the secondary phase, respectively.

These findings were confirmed by the indications emerging from Raman scattering measurements (Fig. 4a). The Raman-allowed phonon modes at $224\left(A_{1 \mathrm{~g}}\right), 244\left(E_{\mathrm{g}}\right), 293\left(E_{\mathrm{g}}\right), 407$ $\left(E_{\mathrm{g}}\right), 496\left(A_{1 \mathrm{~g}}\right)$ and $609 \mathrm{~cm}^{-1}\left(E_{\mathrm{g}}\right)[46,47,48,49]$, as well as the IR-mode at $660 \mathrm{~cm}^{-1}\left(E_{\mathrm{u}}\right)$, which becomes Raman active in nanocrystalline $\alpha-\mathrm{Fe}_{2} \mathrm{O}_{3}[46,47,49]$, were detected in the lower-frequency region of the micro-Raman spectrum of sample Fe (spectrum a in Fig. 4a), whereas the very intense band originating from two-magnon scattering at $1315 \mathrm{~cm}^{-1}$ dominated the higher-frequency region of the spectrum $[46,47]$. In the lower-frequency region of the spectrum of sample FeSi (spectrum $b$ in Fig. 4a), the three broad Raman bands peculiar to $\gamma-\mathrm{Fe}_{2} \mathrm{O}_{3}$, a Fe-deficient form of magnetite $\left(\mathrm{Fe}_{3-}\right.$ ${ }_{x}^{3+}{ }_{x} \mathrm{O}_{4}{ }^{-2}$, with $\mathrm{Fe}$-vacancies in octahedral sites of the lattice [50,51]), were detected at $360\left(T_{1 \mathrm{~g}}\right)$, $510\left(E_{\mathrm{g}}\right), 705 \mathrm{~cm}^{-1}\left(A_{\mathrm{gg}}\right)[19,52]$, together with three narrower bands, associated to the most intense phonon modes of the secondary hematite phase. In the higher frequency region, the maghemite magnon-modes at around 1410 and $1580 \mathrm{~cm}^{-1}$ overlapped to the asymmetric feature arising from two-magnon scattering in $\alpha-\mathrm{Fe}_{2} \mathrm{O}_{3}[19,52]$.

The average size the oxide crystallites in samples $\mathrm{Fe}$ and $\mathrm{FeSi}$, as estimated from the most prominent peak of the diffraction patterns via the Scherrer equation, was 20 and $15 \mathrm{~nm}$, respectively.

As concerns the composite fibres (obtained via a double-step heat process), in the diffraction pattern of sample PFeG (not shown for briefness), only the most intense peaks of the rhombohedral $\alpha-\mathrm{Fe}_{2} \mathrm{O}_{3}$ phase, at $33.3^{\circ}, 35.8^{\circ}, 49.6^{\circ}, 54.2^{\circ}, 62.6^{\circ}$ and $64.2^{\circ} 2 \theta$-angles, were detected. The peaks, corresponding to the reflections from (104), (110), (024), (116), (214) and (030) crystalline planes, were broader than in sample Fe. As a result, the estimation of the average crystallite size from the Scherrer equation in this sample provided a smaller value (Table 2). The results of Raman scattering measurements (not shown) confirmed the formation of nanocrystalline hematite.

In the XRD pattern of sample PMnG (pattern c in Fig. 3), three broad peaks were detected at $35.2^{\circ}, 40.8^{\circ}$ and $59.3^{\circ} 2 \theta$-angles. They were ascribed to the reflections from (111), (200) and (220) crystalline planes of the cubic MnO (JCPDS card No. 75-0626) [18,24,53]. However, the asymmetric shape of the lower $2 \theta$-angle peak revealed the presence of birnessite-type $\mathrm{MnO}_{2}$ (JCPDS card No. 86-0666) as a secondary crystalline phase, finally leading to a non-stoichiometric form of the oxide $\left(\mathrm{MnO}_{\mathrm{x}}\right)$. In fact, the most intense XRD signal from birnessite-type $\mathrm{MnO}_{2}$, whose formation had been reported by other authors in $\mathrm{MnO}_{2}$ /graphene hybrid [26], was located at $36.6^{\circ}$.

The micro-Raman spectrum of sample PMnG, as occurred also for samples PTi and PZn (spectra e and $\mathrm{f}$ in Fig. 4a), was dominated by the very broad and intense D- and G-bands associated to the amorphous $\mathrm{C} s p^{2}$ component of the composite fibres. The very weak spectral features originating from the $\mathrm{MnO}_{\mathrm{x}}$ vibration modes were visible in the lower-frequency region of the spectrum (spectrum a in Fig. 4c), overlapped to the very broad and structured band arising from disorder-related modes in the carbon matrix (see lower-frequency region of Fig. 4b) [13]. The most intense of them, ascribable to the manganese monoxide, was the peak at $654 \mathrm{~cm}^{-1}$, detected also in $\mathrm{MnO} / \mathrm{N}-$ doped carbon composites [21].

Different from the case of sample PMnG, in the spectrum of sample PMn (spectrum c in Fig. 4a) the Raman fingerprint of the manganese dioxide was clearly visible in the lower-frequency region [22]. $\mathrm{MnO}_{2}$ crystallises in three different phases $(\alpha, \beta$ and $\gamma)$, which exhibit quite similar Raman profiles, with the most intense peaks (between 500 and $700 \mathrm{~cm}^{-1}$ ) originating from the stretching mode of $\mathrm{MnO}_{6}$ octahedra and the weaker spectral features (between 200 and $400 \mathrm{~cm}^{-1}$ ) corresponding to the bending mode of $\mathrm{O}-\mathrm{Mn}-\mathrm{O}$ bonds, indicative of the formation of $\mathrm{Mn}_{2} \mathrm{O}_{3}$ or $\mathrm{Mn}_{3} \mathrm{O}_{4}$ [22]. In sample PMn, a sharp peak centred at $650 \mathrm{~cm}^{-1}$ and a shoulder at $562 \mathrm{~cm}^{-1}$ were 
detected, as well as two weaker bands at 325 and $365 \mathrm{~cm}^{-1}$, which suggested that $\beta-\mathrm{MnO}_{2}$ was the dominant phase [22].

The average size the $\beta-\mathrm{MnO}_{2}$ crystallites, as estimated from the most prominent peak of the diffraction pattern (not shown for briefness) via the Scherrer equation, was $30 \mathrm{~nm}$. In full agreement with the indications emerging from Raman analysis, three additional diffraction peaks were detected at $29.2^{\circ}, 32.6^{\circ}$ and $36.4^{\circ}$. They corresponded to the most intense diffraction peaks from (112), (103) and (211) basal planes of the hausmannite $\left(\mathrm{Mn}_{3} \mathrm{O}_{4}\right.$, JCPDS card No. 24-0734) [27].

The diffraction pattern of sample PFe (pattern $d$ in Fig. 3) consisted of five peaks located at $30.1^{\circ}, 35.4^{\circ}, 43.1^{\circ}, 57.0^{\circ}, 62.6^{\circ} 2 \theta$-angles. They could be indexed to the reflections from (220), (311), (400), (511) and (440) crystalline planes of the inverse cubic spinel phase of magnetite $\left(\mathrm{Fe}_{3} \mathrm{O}_{4}\right.$, JCPDS card No. 85-1436) [23,54,55,56]. A smaller contribution from maghemite, which exhibits a very similar diffraction pattern [19], could not be ruled out. The estimation of the average size of $\mathrm{Fe}_{3} \mathrm{O}_{4}$ crystallites from the (311) diffraction peak at $35.4^{\circ}$ led to a value of $31 \mathrm{~nm}$.

The results of Raman scattering measurements (spectrum d in Fig. 4a) fully confirmed the formation of magnetite, to which the broad $T_{2 \mathrm{~g}}\left(330 \mathrm{~cm}^{-1}\right), E_{\mathrm{g}}\left(520 \mathrm{~cm}^{-1}\right)$ and $A_{1 \mathrm{~g}}\left(660 \mathrm{~cm}^{-1}\right)$ peaks could be ascribed, and revealed that a small amount of maghemite was also present, as suggested by the $A_{1 \mathrm{~g}}$ peak $\left(705 \mathrm{~cm}^{-1}\right.$ ), peculiar to this phase [23,55]. The detection (at 223, 288 and $405 \mathrm{~cm}^{-1}$ ) of some sharper features attributable to hematite, together with the band arising from the two-magnon scattering at $1315 \mathrm{~cm}^{-1}$ overlapped to the D-band of the carbonaceous matrix, was understood as the effect of the laser heating, which, as reported also by other authors [23,55], easily induces a local phase transformation even at extremely low laser power (as that here utilised to excite Raman scattering).

The XRD analysis revealed that two distinct phases were present in sample PTi (pattern e in Fig. 3), namely osbornite ( $\mathrm{TiN})$ and titanium dioxide $\left(\mathrm{TiO}_{2}\right)$, with average crystallite sizes of 34 and $25 \mathrm{~nm}$, respectively. In particular, diffraction peaks at $36.3^{\circ}, 42.1^{\circ}$ and $61.2^{\circ} 2 \theta$-angles corresponded to the reflections from (111), (200) and (220) crystalline planes of osbornite (JCPDS card No. 87-0633) [28], whereas the XRD signals at $25.3^{\circ}, 38.6^{\circ}, 48.0^{\circ}, 53.9^{\circ}, 54.7^{\circ}$ were ascribed to anatase and rutile crystallisation phases of $\mathrm{TiO}_{2}$ that are generally present in titanium oxynitride nanostructures [28]. Instead, only the $E_{\mathrm{g}}\left(450 \mathrm{~cm}^{-1}\right)$ and $A_{1 \mathrm{~g}}\left(630 \mathrm{~cm}^{-1}\right)$ of rutile were identified in the lower frequency region of spectrum b in Fig. 4c. Their slightly upshifted positions were probably indicative of the occurrence of compressive stress on $\mathrm{TiO}_{2}$ nanoparticles by the carbonaceous matrix.

Eight peaks at $31.7^{\circ}, 34.4^{\circ}, 36.3^{\circ}, 47.5^{\circ}, 56.6^{\circ}, 62.9^{\circ}, 67.9^{\circ}$ and $69.0^{\circ} 2 \theta$-angles were detected in the diffraction pattern of sample PZn (pattern $\mathrm{f}$ in Fig. 3). They corresponded to the reflections from (100), (002), (101), (102), (110), (103), (112) and (201) crystallographic planes of the hexagonal wurtzite structure of zincite (JCPDS card No. 36-1451) [57,58]. The average size the zincite crystallites, as estimated from the most intense (101) peak via the Scherrer equation, was 14 $\mathrm{nm}$.

In the Raman spectrum of the sample (spectrum c in Fig. 4c), only the most intense among the six normal phonons predicted by the factor group analysis for the wurtzite-type $\mathrm{ZnO}[59,60]$ was clearly visible at about $450 \mathrm{~cm}^{-1}$. Also in this case, the upshifted position of the $E_{2}$ (high) mode was probably indicative of compressive stress affecting $\mathrm{ZnO}$ nanoparticles.

3.1.3 Chemical environment of the component species at the fibre surface. Figures S4 and 5 show the main results of the XPS analysis carried out on the electrospun fibrous nanomaterials to investigate the chemical environment of the component species at the fibre surface.

Figures S4a and S4b respectively show the high-resolution photoelectron spectra of $\mathrm{C} 1 \mathrm{~s}$ and $\mathrm{N} 1 s$ core levels in the carbon-containing fibres. GNCFs, GNC/OFs and NC/OFs were found to exhibit common characteristics. In particular, $\mathrm{C}-\mathrm{N}$ species (at $285.3 \mathrm{eV}$ in the $\mathrm{C} 1 s$ profiles $[13,20,61]$ ) were present in all the samples, whereas pyridinic-nitrogen (at $398.5 \mathrm{eV}$ in the $\mathrm{N} 1 s$ profiles $[13,61,62,63,64,65,66])$ was always the most abundant $\mathrm{N}$-species. Also the N/C atomic ratio, which in GNC/OFs and NC/OFs ranged between 0.203 (sample PTi) and 0.250 (sample 
PMn), was very close to that previously measured in GNCFs (0.238 [13]) (Table 3). The latter finding confirmed that the choice of a polymer (PAN) with a high $\mathrm{N}$-content $(26.4 \mathrm{wt} \%)$ and of a low carbonisation temperature $\left(500^{\circ} \mathrm{C}\right)$ is an effective strategy to produce composite fibres with high nitrogen-doping levels. Oxygenated-C species, generated during the stabilisation step, were also present on the surface of the carbonaceous component of the fibres (Table 3). Their presence is beneficial for wettability and pseudocapacitance, as well $[41,67]$. Information about the oxide in the OFs, as well as the oxide component in the GNC/OFs and NC/OFs, was inferred from the highresolution XPS (HRXPS) spectra of the transition-metal $2 p$ core level (Fig. 5).

The HRXPS spectrum of Fe $2 p$ core level in sample Fe (profile a in Fig. 5a) was featured by two spin-orbit components at binding energies (BEs) of $710.6 \mathrm{eV}\left(2 p_{3 / 2}\right)$ and $724.7 \mathrm{eV}\left(2 p_{1 / 2}\right)$ and by the $\mathrm{Fe}^{3+}$ shake-up satellite at $717.5 \mathrm{eV}$, as reported in literature for the hematite phase of iron oxide $[19,68,69]$, which was consistent with indications come out from XRD and MRS analyses. As expected [19,70,71], the incorporation of silicon within the $\mathrm{Fe}_{2} \mathrm{O}_{3}$ lattice (sample $\mathrm{FeSi}$ ) did not introduce evident changes in the spectrum (profile b in Fig. 5a), whereas the BE position of the Si $2 p$ peak (> $99.4 \mathrm{eV}$, see inset of Fig. 5a) allowed ruling out the presence of elemental silicon $\left(\mathrm{Si}^{0}\right)$. No $\mathrm{Fe}^{3+}$ shake-up satellite between the two $2 p_{3 / 2}-2 p_{1 / 2}$ spin-orbit components was detected in sample PFe (profile $\mathrm{c}$ in Fig. 5a). This finding, together with the lower BE of the main peak (710.4 $\mathrm{eV}$ ), further supported the formation of magnetite evidenced by XRD and MRS analyses [55,56,72].

Figure $5 \mathrm{~b}$ displays the HRXPS spectra of Mn $2 p$ core level in samples PMn and PMnG (profiles a and $b$, respectively). In sample PMnG the two spin-orbit components were located at $641.3 \mathrm{eV}\left(2 p_{3 / 2}\right)$ and $653.3 \mathrm{eV}\left(2 p_{1 / 2}\right)$, and the $\mathrm{Mn}^{2+}$ shake-up satellite was interposed between them. This indicated the presence of $\mathrm{MnO}[18,24]$, as revealed by the XRD analysis. Instead, in sample PMn no satellite structure was detected and the two $2 p_{3 / 2}-2 p_{1 / 2}$ spin-orbit components, with a separation of $11.7 \mathrm{eV}$, were located at slightly higher BEs, suggesting the presence of Mn cations with higher oxidation state [29], in agreement with the indications emerged from the MRS analysis.

In the high-resolution photoelectron spectrum of Ti $2 p$ core level in sample PTi (Fig. 5c), the two $2 p_{3 / 2}-2 p_{1 / 2}$ spin-orbit components were located at slightly lower BEs with respect to anatase and rutile phases of $\mathrm{TiO}_{2}$ (458.2 against $459.5 \mathrm{eV}$, and $464.0 \mathrm{eV}$ against $465.2 \mathrm{eV}$ [30]). Since even lower BE positions (457.5 and $463.0 \mathrm{eV}$ for $2 p_{3 / 2}$ and $2 p_{1 / 2}$ components, respectively) had been reported for titanium oxynitride $\mathrm{TiO}_{\mathrm{x}} \mathrm{N}_{\mathrm{y}}$ [28], the observed downshift was understood as the effect of the formation of osbornite revealed by the XRD analysis. On the other hand, the position of the peak associated to lattice oxygen in the spectrum of $\mathrm{O} 1 \mathrm{~s}$ core level $(529.6 \mathrm{eV}$, see inset of Fig. 5c) was closer to that of rutile (529.4 eV [73]) rather than to that of anatase (531.0 eV [30]), in agreement with the results of Raman scattering measurements.

Finally, in the HRXPS spectrum of Zn $2 p$ core level in sample PZn (Fig. 5d) the $2 p_{3 / 2}$ spin-orbit component was located at a BE of $1021.4 \mathrm{eV}$, with a separation of $23.0 \mathrm{eV}$ from the $2 p_{1 / 2}$ component. Thus, it confirmed the presence of $\mathrm{Zn}^{2+}$ species [74], as resulted from XRD and MRs analyses.

\subsection{Electrochemical properties of the electrodes using electrospun fibres as active materials}

In order to evaluate the electrochemical performance of the considered GNCFs, NC/OFs and GNC/OFs as active materials for CDI electrodes (Table 4) and to ascertain the formation of the electrical double-layer (EDL), CV measurements were carried out in $0.1 \mathrm{M} \mathrm{NaCl}$ solutions at different scan rates $\left(5,10,20,30,40,50\right.$ and $\left.100 \mathrm{mV} \mathrm{s}^{-1}\right)$. The curves obtained by investigating the potential window between -1 and $0.5 \mathrm{~V}$ are shown in Figure 6. They confirmed the EDL formation for all the electrodes.

Nonetheless, in agreement with the behaviour observed for GNCFs in a previous study [13], the anodic region of the CV curve relative to electrode PG (Figure 6a), here regarded as a reference, showed a slight deviation from the ideal rectangular shape of the EDL, which became more evident at higher scan rates. The CV curves relative to electrodes PGmixFe and PGmixFeSi, PFeG, PMnG and PMn (Figures 6b, c, d, e and f, respectively) showed analogous, or even more marked 
deviations. On the contrary, the shape of CV curves of the remaining electrodes (PFe, PTi and PZn) was more similar to the ideal one.

Deviations from the EDL behaviour, indicated the occurrence of Faradaic pseudo-capacitive charge-transfer reactions [75,76], probably associated to the presence of an appreciable amount of nitrogen functional groups in the active material [35], as already pointed out [13]. Actually, as mentioned above, all the types of fibres produced (GNCFs, GNC/OFs and NC/OFs) exhibited comparable N/C atomic ratios (0.203-0.250). This finding substantially reflected the limited the evolution of volatile $\mathrm{N}$-containing by-products occurred at the low carbonisation temperature selected [45]. Hence, a deeper understanding of the different behaviours observed required some additional consideration.

In line with the previous findings on composite electrospun fibres containing different oxides [20], the samples (PFeG, PMnG and PMn) prepared by utilising a spinnable solution with $2.50 \mathrm{wt} \%$ TM load obviously contained a smaller amount of oxide with respect to those (PFe, PTi and PZn) prepared, under the same heat treatment conditions, from solutions with higher TM load (25-31 $\mathrm{wt} \%$ against 54-57 wt $\%$, as estimated from the atomic concentrations inferred from the XPS analysis). Thus, overall, the $\mathrm{N}$-doped carbonaceous component of the latter was smaller than that of the former (Table 4). This caused samples PFe, PTi and PZn to be featured by a smaller relative content of nitrogen (7.2-7.3 wt\%), with respect to samples PFeG, PMnG and PMn (where the Ncontent ranged between 13.7 and $15.0 \mathrm{wt} \%$ ). Finally, since the N-content of the GNCFs (sample PG) was $19.3 \mathrm{wt} \%$ [13], the physical mixtures (PGmixFe and PGmixFeSi) with 1:1 GNCFs:OFs mass ratio contained approximately $9.7 \mathrm{wt} \%$ of nitrogen. The variation of $\mathrm{N}$-concentration in the considered fibrous electrode materials accounted, at least in part, for the observed deviations from the "pure-EDL" behaviour.

Generally, materials possessing superior capacitive performance exhibit better electro-sorption properties. Therefore, the specific capacitance, $C_{\mathrm{S}}$, of the electrodes based on the electrospun TMOs (GNC/OFs and NC/OFs) was calculated, via eq.(1), from the CV curves shown in Figure 6. Figure 7 compares the results obtained at the considered scan rates. At the lowest scan rate, the highest capacitance pertained to PMnG $\left(67.7 \mathrm{Fg}^{-1}\right)$, whose $S_{\text {BET }}$ was comparable to that of PG $\left(\sim 17 \mathrm{~m}^{2} \mathrm{~g}^{-1}\right)$. $\mathrm{PFe}$ and PMn exhibited comparable $S_{\mathrm{BET}}$ and $C_{\mathrm{S}}$ values $\left(11.2\right.$ and $11.5 \mathrm{~m}^{2} \mathrm{~g}^{-1}$, and 67.4 and $66.3 \mathrm{~F}$ $\mathrm{g}^{-1}$, respectively). The capacitance of the remaining electrodes decreased in the order PTi (56.6 F $\left.\mathrm{g}^{-1}\right)>\mathrm{PZn}\left(55.5 \mathrm{Fg}^{-1}\right)>$ PGmixFe $\left(53.7 \mathrm{~F} \mathrm{~g}^{-1}\right)>\mathrm{PFeG}\left(49.7 \mathrm{Fg}^{-1}\right)>$ PGmixFeSi $\left(46.7 \mathrm{~F} \mathrm{~g}^{-1}\right)$. As can be seen in Figure S5, all these values were significantly lower than that of the GNCF-based reference electrode PG $\left(136.4 \mathrm{~F} \mathrm{~g}^{-1}\right)$, as well as of the previously studied NCF-based electrode (105.5 $\mathrm{F} \mathrm{g}^{-1}$ [13]). For the preparation-conditions and properties of the latter electrode material (below coded as P) see Tables S1-S3.

Nonetheless, at $10 \mathrm{mV} \mathrm{s}^{-1}$, the specific capacitance of electrode PZn $\left(43.7 \mathrm{~F} \mathrm{~g}^{-1}\right)$ largely exceeded the values $\left(20-30 \mathrm{~F} \mathrm{~g}^{-1}\right)$ reported, at the same scan rate in $0.5 \mathrm{M} \mathrm{NaCl}$ solution, for electrodes consisting of zinc oxide nanoparticles, nanorods, microsheets and microspheres grafted on activated carbon cloth [77]. At $5 \mathrm{mV} \mathrm{s}^{-1}$ scan rate, $\mathrm{PMnG}, \mathrm{PFe}$ and $\mathrm{PMn}$ exhibited higher capacitance with respect to $\mathrm{RuO}_{2}$-activated carbon composite electrodes $\left(60.6 \mathrm{~F} \mathrm{~g}^{-1}\right)$, able to remove $11.26 \mathrm{mg} \mathrm{g}^{-1}$ of salt from a $5 \mathrm{mM} \mathrm{NaCl}$ solution at $1.2 \mathrm{~V}$ [17]. Instead, at the same rate, a greater $C_{\mathrm{S}}$ value was achieved with graphene aerogel/ $\mathrm{TiO}_{2}$ metal oxide hybrids $\left(119.7 \mathrm{~F} \mathrm{~g}^{-1}\right)$ [3], whereas carbon aerogels doped with manganese or iron oxides prepared by the resorcinol-formaldehyde exhibited greater capacitance (91 and $99 \mathrm{~F} \mathrm{~g} \mathrm{~g}^{-1}$, respectively) at a very low scan rate $\left(0.5 \mathrm{mV} \mathrm{s}^{-1}\right)$ [16].

The contribution, $C_{\mathrm{TMO}}$, provided by the oxide to the overall capacitance of the hybrid material, $C_{\mathrm{S}}=\left(w_{\mathrm{C}} C_{\mathrm{C}}+w_{\mathrm{TMO}} C_{\mathrm{TMO}}\right) / 100$, was estimated taking into account its relative content, $w_{\mathrm{TMO}}$, as inferred from the XPS analysis (Table 3) and the specific capacitance of its carbonaceous component, $C_{\mathrm{C}} . C_{\mathrm{TMO}}$ was found to strongly vary case by case. For instance, in the case of electrode PFe (whose active material was composed by $54 \mathrm{wt} \%$ of magnetite), by subtracting from the total 
capacitance at $5 \mathrm{mV} \mathrm{s}^{-1}$ rate $\left(67.4 \mathrm{Fg}^{-1}\right)$ the contribution associated to the carbonaceous component of the fibres $\left(48.6 \mathrm{~F} \mathrm{~g}^{-1}\right.$, for $w_{\mathrm{C}}=46 \mathrm{wt} \%$, having used the value of the NCFs at the same rate, $C_{\mathrm{C}}=$ $105.5 \mathrm{~F} \mathrm{~g}^{-1}$ [13]), a residual value of $18.8 \mathrm{~F} \mathrm{~g}^{-1}$ was obtained. This value corresponded to a calculated specific capacitance of $C_{\mathrm{TMO}}=34.9 \mathrm{~F} \mathrm{~g}^{-1}$ for $\mathrm{Fe}_{3} \mathrm{O}_{4}$ and was higher than that reported for supercapacitor with magnetite electrode $\left(25 \mathrm{~F} \mathrm{~g}^{-1}\right)$ in aqueous $1 \mathrm{M} \mathrm{Na}_{2} \mathrm{SO}_{4}$ solution [78], hinting at a synergy between the two mechanisms (EDL-capacitive and redox-pseudocapacitive) through which ion storage takes place in the hybrid material.

Instead, at the same scan rate, using the same criterion, in the case of electrode PMn (whose active material contained $31 \mathrm{wt} \%$ of $\mathrm{MnO}_{2}$ ), the contribution expected for the carbonaceous component of the fibres $\left(73.1 \mathrm{~F} \mathrm{~g}^{-1}\right.$ since $w_{\mathrm{C}}$ is $\left.69 \mathrm{wt} \%\right)$ exceeded the total measured capacitance $\left(66.3 \mathrm{~F} \mathrm{~g}^{-1}\right)$, hinting at a bad performance of both the material components. This suggested that the morphology of the composite fibres plays a relevant role in determining their electrochemical performance. The "wheat ear-like" morphology of sample PFe (Fig. 1b) favoured the intimate contact between the two material components and produced a beneficial effect in terms of overall specific capacitance, whereas the "usnea florida lichen-like" morphology of sample PMn (Fig. 1a), with large oxide agglomerates (and, thus, small $S_{\mathrm{BET}}$ ) and poor interaction between the conductive $\mathrm{N}$-doped carbon and the oxide, resulted in worse performance, due to inhibition of the EDL capacitive behaviour and limited electron-transport [17].

As already pointed out, a high $\mathrm{N}$-doping level of the active material is beneficial for the wettability of the electrode surface [4,13,14,35,36,37]. Indeed, also oxygenated-C species, generated during the stabilisation process on the surface of the carbonaceous component of the fibres, may contribute to improve the wettability and pseudocapacitance [41,67], as well. Actually, at fixed scan rate, by plotting the specific capacitance of the considered electrodes as a function of the overall amount of surface nitrogen and carbon-bonded oxygen of the active material, a good correlation was found (Figure 8), even if the relative weights of $\mathrm{N}$ in sample PTi and of carbonbonded oxygen in sample PMnG might have been slightly overestimated owing to the presence of a secondary TM-related phase. The existence of this correlation proven that both the surface functional species (SFSs) of the carbonaceous component of the fibres contributed in improving wettability and enhancing $C_{\mathrm{S}}$.

Additional information was inferred by evaluating the effective areal capacitance $\left(C_{\mathrm{A}}\right)$, which indirectly gives a measure of the amount of the CDI-active pores [79]. In carbons synthesised from biomass materials, usually endowed with extremely large $S_{\mathrm{BET}}$ (even $>3000 \mathrm{~m}^{2} \mathrm{~g}^{-1}$ ), $C_{\mathrm{A}}$, calculated as $C_{\mathrm{S}} / S_{\mathrm{BET}}$ ratio, had been reported to vary in the range $7-29 \mu \mathrm{F} \mathrm{cm}^{-2}$ [79]. For $v=5 \mathrm{mV} \mathrm{s}^{-1}$, the $C_{\mathrm{A}}$-values obtained for the present electrospun electrode materials, featured by greatly smaller $S_{\mathrm{BET}}$ (11-42 $\left.\mathrm{m}^{2} \mathrm{~g}^{-1}\right)$, were one order of magnitude larger $\left(120-810 \mu \mathrm{F} \mathrm{cm}^{-2}\right)$. This finding was in line with what previously pointed out by Huang et al. [41], i.e. that the use of extremely high surface area carbons might be unprofitable since micropores, which contribute to enhance the material $S_{\mathrm{BET}}$, are hardly accessible for the ions and, hence, not active in CDI process [41]. Indeed, $C_{\mathrm{A}}$ was found to depend not only on the relative amount of SFSs $\left(\mathrm{N}\right.$ and $\mathrm{O}_{\mathrm{C}}$ ), but also on the $V_{\text {MP }}$ (Figure 9). The highest $C_{\mathrm{A}}$-value pertained to $\mathrm{PG}$, where the small $V_{\mathrm{MP}}\left(1.3 \mathrm{~mm}^{3} \mathrm{~g}^{-1}\right)$ was associated to the largest amount of SFSs (30.6 wt \%). $C_{\mathrm{A}}$ progressively decreased as the SFS-content diminished and/or the $V_{\mathrm{MP}}$ increased. In PFeG, featured by a large $V_{\mathrm{MP}}\left(5.6 \mathrm{~mm}^{3} \mathrm{~g}^{-1}\right)$ and $18.3 \mathrm{wt} \%$ of SFSs, $C_{\mathrm{A}}$ dropped down to $1.2 \mathrm{~F} \mathrm{~m}^{-2}$, although the average size of its pores was comparable to that of PG (4.7 against $4.6 \mathrm{~nm})$.

In agreement with the literature [4], the increase of scan rate from 5 to $100 \mathrm{mV} \mathrm{s}^{-1}$ produced a remarkable decrease of $C_{\mathrm{S}}$ values in all of the investigated electrodes (Figure S6a). $C_{\mathrm{S}}$ dropped from 67.4 down to $17.5 \mathrm{~F} \mathrm{~g}^{-1}(-74.0 \%)$ in PFe, from 67.7 down to $8.8 \mathrm{~F} \mathrm{~g}^{-1}(-87.0 \%)$ in PMnG, from 66.3 down to $10.8 \mathrm{~F} \mathrm{~g}^{-1}(-83.7 \%)$ in PMn, from 56.7 down to $15.6 \mathrm{~F} \mathrm{~g}^{-1}(-72.6 \%)$ in PTi, from 55.5 down to $15.3 \mathrm{Fg}^{-1}(-72.5 \%)$ in PZn, from 53.7 down to $13.3 \mathrm{Fg}^{-1}(-75.2 \%)$ in PGmixFe, from 49.7 down to $11.7 \mathrm{~F} \mathrm{~g}^{-1}$ in $\mathrm{PFeG}(-76.5 \%)$ and from 46.7 down to $10.2 \mathrm{~F} \mathrm{~g}^{-1}(-78.1 \%)$ in PGmixFeSi. 
The same calculation provided a $C_{\mathrm{S}}$ decrease of $-83.1 \%$ and $-83.9 \%$ for the electrodes based on NCFs and GNCFs, for which, under the same conditions, $C_{\mathrm{S}}$ was respectively 105.5 and $136.4 \mathrm{Fg}^{-1}$ at a scan rate of $5 \mathrm{mV} \mathrm{s}^{-1}$ and 17.8 and $22.0 \mathrm{~F} \mathrm{~g}^{-1}$ at $100 \mathrm{mV} \mathrm{s}^{-1}$ [13].

This behaviour was related to the existence of less accessible surface regions, which were progressively excluded, as the rate of reaction was enhanced [80]. At low scanning rates, in fact, the ions of the electrolyte had enough time to diffuse into the inner pores of the electrodes, which is essential for the formation of the EDL. As the scan rate increased, the diffusion became ratelimiting [80]: diffusion time, inversely proportional to scan rate [80], was not enough for the ions to move and accumulated into the inner pores. As a result, in the former situation, a larger fraction of the ions was stored on the surface of the electrodes both electrostatically and electrochemically (i.e. through EDL-capacitive and pseudocapacitive processes, respectively), whereas, in the latter, the fraction of adsorbed ions diminished, causing the observed capacitance decrease. At low scan rate, the (reference) GNCFs fully profited of the presence on their surface of a large fraction of mesopores and macropores (inset of Fig. 2a), as well as of a great amount of $\mathrm{N}$ - and Ofunctionalities enhancing their wettability (Figure 8), with graphene-enrichment affording for higher conductivity and capacitance [13]. At the higher scan rates, the ion diffusion became rate limiting, causing a dramatic drop of $C_{\mathrm{S}}$.

Interestingly, the average rate at which $C_{\mathrm{S}}$ decreased with increasing scan rate (v), qualitatively giving a measure of the impact of diffusion as the rate-limiting process (with more negative $\Delta C_{\mathrm{S}} / \Delta v$ values indicating a heavier impact), was by far larger in the case of the (reference) GNCFs and previously studied NCFs [13]). It remarkably reduced in the presence of the TMO (Figure S6b), regardless of whether this latter was part of a physical mixture or of a composite material (NC/OFs or GNC/OFs). As a general trend, the larger the TMO relative-content, the slower the $C_{\mathrm{S}}$ decrease with increasing $v$ (Figure 10). The only exception was electrode PFeG, where the active material exhibited the largest $S_{\text {BET }}\left(\sim 42 \mathrm{~m}^{2} \mathrm{~g}^{-1}\right)$ among those considered. This suggested that, in the hybrid materials, where ion storage occurs via a mixed EDL/Faradaic process [17], the contribution to the overall capacitance associated to the fast charge-transfer reactions involving the TMO partly compensated for the diffusion-related decrease of electrostatic adsorption occurring at higher scanrates. In PFeG (with only $29.3 \mathrm{wt} \%$ of $\mathrm{Fe}_{2} \mathrm{O}_{3}$ ), the larger $S_{\mathrm{BET}}$, although rendered partly inactive due to the greater $V_{\mathrm{MP}}$ (Table 2), limited the effect due to the reduction of accessible surface as the rate of reaction was enhanced.

The electrochemical behaviour of the prepared with the GNCFs, NC/OFs and GNC/OFs electrodes was evaluated also by EIS analysis, recognized as one of the principal methods to examine the inner resistivity of the as-prepared electrode material [75]. Figure 11 displays the most representative results of the EIS measurements, carried out in solution with $0.1 \mathrm{M} \mathrm{NaCl}$ concentration.

Except for PGmixFeSi (Figure 11a), the plots were featured by a straight line in the lowfrequency region, ascribed to the Warburg impedance, which depends on the kinetics of the ion diffusion in the solution, and on the adsorption of ions onto the electrode surface [32,81]. Theoretically, the Nyquist plot for a pure capacitor should consist in a line perpendicular to the real axis [82]. The lower slope $\left(45.7-48.9^{\circ}\right)$ measured in the Nyquist plots of the investigated electrodes clearly indicated a deviation from the ideal behaviour, confirming the above-discussed occurrence of Faradaic processes that have great relevance in carbon-based electrode materials for desalination by CDI [41]. In PGmixFeSi, the slope underwent a change (from $\sim 49^{\circ}$ to $\sim 30^{\circ}$ ) at $\sim 650 \mathrm{mHz}(300$ $\Omega$ ). This behaviour was understood as the effect of the existence of two different ion diffusion mechanisms, due to the coexistence of two distinct components (GNCFs and OFs) in the physical mixture.

In the mid-high frequency region of electrodes PG, PGmixFeSi and PFeG (Figures 11a-b), a semicircle was visible, associated to the formation of the EDL close to the electrode/electrolyte interface. It corresponded to a parallel combination of the charge-transfer resistance and the EDL capacitance [14], as resulted from the contact between the electrode and current collector and the 
resistance of the porous electrode itself [32]. The size of the semicircle increased as the barrier for ions' entry to the pores enhanced [83] and the resistance value (that corresponds to the intercept of the plot with the real axis) varied in the order PG $(53 \Omega)<\operatorname{PFeG}(66 \Omega)<$ PGmixFeSi $(95 \Omega)$, that is in the opposite order with respect to the relative content of the GNC-component of the fibres (100, 71 and $50 \mathrm{wt} \%$, respectively), confirming that graphene incorporation in the NCF-based electrode material was beneficial to the charge transfer on the electrode [13]. As for the graphenefree composite NC/OFs (Figures 11b-c), the resistance varied in the order PTi $(69 \Omega)>\mathrm{PFe}(63 \Omega)$ $>$ PZn $(60 \Omega)$ with no evident correlation with the relative amount of the NC-component of the fibrous material.

\section{Conclusions}

The physicochemical properties of electrospun composite fibrous materials based on (graphene-enriched) nitrogen-doped carbon/transition metal oxides, (G)N-C/OFs, were thoroughly investigated by a combination of characterisation techniques. Besides, the electrochemical behaviour of the electrodes prepared with them was evaluated in view of their possible use in CDIcells for water desalination, and the existence of interesting correlations between the physicochemical and electrochemical properties was evidenced.

The produced materials contained from 24.6 to $56.7 \mathrm{wt} \%$ of oxide and exhibited different (usnea florida lichen-, wheat ear-, sea sponge- and noodle-like) morphologies, which depended on the transition metal ( $\mathrm{Mn}, \mathrm{Fe}, \mathrm{Ti}$ or $\mathrm{Zn}$ ). Thanks to the low carbonisation temperature selected $\left(500^{\circ} \mathrm{C}\right)$, they were featured by moderate specific surface area $\left(11-42 \mathrm{~m}^{2} \mathrm{~g}^{-1}\right)$ and micropore volume $\left(0.4-5.6 \mathrm{~mm}^{3} \mathrm{~g}^{-1}\right)$ and by high relative amount $(14.1-22.2 \mathrm{wt} \%)$ of surface nitrogen and carbon-bonded oxygen functional species.

Concentration of the surface species, which improve wettability and involve Faradaic processes, and morphology strongly affected the specific capacitance $\left(43.7-67.4 \mathrm{~F} \mathrm{~g}^{-1}\right.$, at $5 \mathrm{~m} \mathrm{~V} \mathrm{~s}^{-1}$ scan rate) of the electrodes prepared with these fibrous materials.

Their effective areal capacitance $\left(1.2-6.0 \mathrm{~F} \mathrm{~m}^{-2}\right.$, at $5 \mathrm{~m} \mathrm{~V} \mathrm{~s}^{-1}$ ) benefited from the abundance of surface functional species and the moderate specific surface area and micropore volume of the active material.

The investigated composite materials stored ions via a mixed capacitive/pseudocapacitive process. Therefore, increasing the content of the oxide that involves fast reversible redox reactions at or near surface partly compensated for the growing hindrance to diffusion encountered by the ions and resulting in hampered electrostatic adsorption at high scan rate.

\section{References}

[1] Y. Oren, Capacitive deionization (CDI) for desalination and water treatment - past, present and future (a review), Desalination 22 (2008) 10-29.

[2] S. Porada, R. Zhao, A. Van der Wal, V. Presser, P.M. Biesheuvel, Review on the science and technology of water desalination by capacitive deionization, Prog. Mater. Sci. 58 (2013) 13881442.

[3] H. Yin, S. Zhao, J. Wan, H. Tang, L. Chang, L. He, H. Zhao, Y. Gao, Z. Tang, Threedimensional graphene/metal oxide nanoparticle hybrids for high-performance capacitive deionization of saline water, Adv. Mater. 25 (2013) 6270-6276.

[4] Z. Wang, T. Yan, J. Fang, L. Shi, D. Zhang, Nitrogen-doped porous carbon derived from a bimetallic metal - organic framework as highly efficient electrodes for flow-through deionization capacitors, J. Mater. Chem. A 4 (2016) 10858-10868.

[5] C. J. Gabelich, T. D. Tran, I. H. Suffet, Electrosorption of inorganic salts from aqueous solution using carbon aerogels, Environ. Sci. Technol. 36 (2002) 3010-3019.

[6] P. Xu, J. E. Drewes, D. Heil, G. Wang, Treatment of brackish produced water using carbon aerogel-based capacitive deionization technology, Water Res. 42 (2008) 2605-2617. 
[7] L. Zou, G. Morris, D. Qi, Using activated carbon electrode in electrosorptive deionisation of brackish water, Desalination 225 (2008) 329-340.

[8] D. Zhang, L. Shi, J. Fang, K. Dai, Influence of diameter of carbon nanotubes mounted in flowthrough capacitors on removal of $\mathrm{NaCl}$ from salt water, J. Mater. Sci. 42 (2006) 2471-2475.

[9] C. Nie, L. Pan, H. Li, T. Chen, T. Lu, Z. Sun, Electrophoretic deposition of carbon nanotubes film electrodes for capacitive deionization, J. Electroanal. Chem. 666 (2012) 85-88.

[10] G. Wang, C. Pan, L. Wang, Q. Dong, C. Yu, Z. Zhao, J. Qiu, Activated carbon nanofiber webs made by electrospinning for capacitive deionization, Electrochim. Acta 69 (2012) 65-70.

[11]G. Wang, Q. Dong, Z. Ling, C. Pan, C. Yu, J. Qiu, Hierarchical activated carbon nanofiber webs with tuned structure fabricated by electrospinning for capacitive deionization, J. Mater. Chem. A 22 (2012) 21819-21823.

[12]Q. Dong, G. Wang, T. Wu, S. Peng, J. Qiu, Enhancing capacitive deionization performance of electrospun activated carbon nanofibers by coupling with carbon nanotubes, J. Colloid Interface Sci. 446 (2015) 373-378.

[13] Y. Belaustegui, S. Zorita, F. Fernández-Carretero, A. García-Luis, F. Pantò, S. Stelitano, P. Frontera, P. Antonucci, S. Santangelo, Electrospun graphene-enriched nitrogen-doped carbon fibres for electrochemical water desalination, Desalination 428 (2018) 40-49.

[14]X. Xu, Z. Sun, D.H.C. Chua, L. Pan, Novel nitrogen doped graphene sponge with ultrahigh capacitive deionization performance, Sci. Rep. 5 (2015) 11225 (9pp).

[15]Q. Dong, G. Wang, B. Qian, C. Hu, Y. Wang, J. Qiu, Electrospun composites made of reduced graphene oxide and activated carbon nanofibers for capacitive deionization, Electrochim. Acta 137 (2014) 388-394.

[16]M. C. Zafra, P. Lavela, G. Rasines, C. Macías, J. L. Tirado, C. O. Ania, A novel method for metal oxide deposition on carbon aerogels with potential application in capacitive deionization of saline water, Electrochim. Acta 135 (2014), 208-216.

[17]X. Ma, Y. A. Chen, K. Zhou, P. C. Wu, C. H. Hou, Enhanced desalination performance via mixed capacitive-Faradaic ion storage using $\mathrm{RuO}_{2}$-activated carbon composite electrodes, Electrochim. Acta 295 (2019) 769-777

[18]X. Zhou, F. Cheng, J. Yang, M. Jia, A. Sun, J. Tang, N-doped carbon encapsulated MnO nanoparticles for enhanced lithium storage, Mater. Lett. 234 (2019) 335-338.

[19]M. Fiore, G. Longoni, S. Santangelo, F. Pantò, S. Stelitano, P. Frontera, P. Antonucci, R. Ruffo, Electrochemical characterization of highly abundant, low cost iron(III) oxide as anode material for sodium-ion rechargeable batteries, Electrochim. Acta 269 (2018) 367-377

[20]F. Pantò, Y. Fan, S. Stelitano, E. Fazio, P. Frontera, S. Patanè, P. L. Antonucci, N. Pinna, S. Santangelo, Are electro-spun fibrous membranes relevant electrode materials for Li-ion batteries? The case of the composite $\mathrm{C} / \mathrm{GeO}_{2}$ fibres, Adv. Functional Mater. 28 (2018) 1800938-1800951

[21]C. G. Han, C. Zhu, Y. Aoki, H. Habazaki, T. Akiyama, MnO/N-C anode materials for lithiumion batteries prepared by cotton-templated combustion synthesis, Green Energy \& Environment 2 (2017) 377-386

[22] Ş. Özcan, A. Güler, T. Cetinkaya, M. O. Guler, H. Akbulut, Freestanding graphene/ $\mathrm{MnO}_{2}$ cathodes for Li-ion batteries, Beilstein J. Nanotechnol. 8 (2017) 1932-1938.

[23]K. Song, Y. Lee, M. R. Jo, K. M. Nam, Y. M. Kang, Comprehensive design of carbonencapsulated $\mathrm{Fe}_{3} \mathrm{O}_{4}$ nanocrystals and their lithium storage properties, Nanotechnology 23 (2012) 505401 (6pp).

[24]L. Gao, C. Gu, J. Zhao , X. Song, J. Huang, Preparation of manganese monoxide@ reduced graphene oxide nanocomposites with superior electrochemical performances for lithium-ion batteries, Ceramics International 45 (2019) 3425-3434.

[25]W. Deng, X. Ji, Q. Chen, C. E. Banks, Electrochemical capacitors utilizing transition metal oxides: an update of recent developments, RSC Advances 1 (2011) 1171. 
[26] Y. Liu, D. Yan, R. Zhuo, S. Li, Z. Wu, J. Wang, P. Ren, P. Yan, Z. Geng, Design, hydrothermal synthesis and electrochemical properties of porous birnessite-type manganese dioxide nanosheets on graphene as a hybrid material for supercapacitors, J. Power Sources 242 (2013) 78-85

[27]T. H. Wu, D. Hesp, V. Dhanak, C. Collins, F. Braga, L. J. Hardwick, C. C. Hu, Charge storage mechanism of activated manganese oxide composites for pseudocapacitors, J. Mater. Chem. A 3 (2015) 12786-12795.

[28]J. Zhang, A. L. Hector, S. Soulé, Q. Zhang, X. Zhao, Effects of ammonolysis and of sol-gel titanium oxide nitride coating on carbon fibres for use inflexible supercapacitors, J. Mater. Chem. A 6 (2018) 5208-5216.

[29]Q. Ma, M. Yang, X. Xia, H. Chen, L. Yang, H. Liu, Amorphous hierarchical porous manganese oxides for supercapacitors with excellent cycle performance and rate capability, Electrochim. Acta 291 (2018) 9-17.

[30]L. Zhu, Q. Lu, L. Lv, Y. Wang, Y. Hu, Z. Deng, Z. Lou, Y. Hou, F. Teng, Ligand-free rutile and anatase $\mathrm{TiO}_{2}$ nanocrystals as electron extraction layers for high performance inverted polymer solar cells, RSC Advances 7 (2017) 20084-20092.

[31]M. Bognitzki, W. Czado, T. Frese, A. Schaper, M. Hellwig, M. Steinhart, A. Greiner, J. H. Wendorff, Nanostructured fibers via electrospinning, Adv. Mater. 13 (2001) 70-72.

[32] C. Kim, B. T. N. Ngoc, K. S. Yang, M. Kojima, Y. A. Kim, Y. J. Kim, M. Endo, S. C. Yang, Self-sustained thin webs consisting of porous carbon nanofibers for supercapacitors via the electrospinning of polyacrylonitrile solutions containing zinc chloride, Adv. Mater. 19 (2007) 2341-2346.

[33] Y. Liang, D. Wu, R. Fu, Carbon Microfibers with Hierarchical porous structure from electrospun fiber-like natural biopolymer, Sci. Rep. 3 (2013) 1119.

[34] W. S. Hummers, R. E. Offeman, Preparation of graphitic oxide, J. Am. Chem. Soc. 80 (1958) 1339-1339.

[35]X. Xu, L. Pan, Y. Liu, T. Lu, Z. Sun, Enhanced capacitive deionization performance of graphene by nitrogen doping, J. Colloid. Interface Sci. 445 (2015) 143-150.

[36] K. Shi, M. Ren, I. Zhitomirsky, Activated carbon-coated carbon nanotubes for energy storage in supercapacitors and capacitive water purification, ACS Sustain. Chem. Eng. 2 (2014) 1289-1298.

[37] Y. Li, J. Shen, J. Li, X. Sun, J. Shen, W. Han,L. Wang, A protic salt-derived porous carbon for efficient capacitive deionization: Balance between porous structure and chemical composition, Carbon 116 (2017) 21-32.

[38] J. M. Syu, M. L. Hsiao, C. T. Lo, Electrospun carbon Fiber/Ni-Co composites as binder-free anodes for lithium-ion batteries. J. Electrochem. Soc. 164 (2017) A3903-A3913.

[39]F. Rouquerol, J. Rouquerol, K.S.W. Sing, P. Llewellyn, G. Maurin, Adsorption by powders and porous solids. (Second Edition) Principles, methodology and applications, Elsevier, Amsterdam, 2014.

[40] M. Thommes, Physical adsorption characterization of nanoporous materials, Chem. Ing. Tech. 82 (2010) 1059-1073.

[41]W. Huang, Y. Zhang, S. Bao, S. Song, Desalination by capacitive deionization with carbonbased materials as electrode: a review, Surf. Rev. Lett. 20 (2013) 1330003 (10p)

[42]A. C. Ferrari, J. Robertson, Interpretation of Raman spectra of disordered and amorphous carbon, Phys. Rev. B 61 (2001) 14095-14107.

[43] S. Santangelo, Controlled surface functionalization of carbon nanotubes by nitric acid vapors generated from sub-azeotropic solution. Surf. Interface Anal. 48 (2016) 17-25.

[44] Y. Wang, S. Serrano, J.J. Santiago-Avilés, Raman characterization of carbon nanofibers prepared using electrospinning, Synth. Met. 138 (2003) 423-427.

[45] M.S.A. Rahaman, A.F. Ismail, A. Mustafa, A review of heat treatment on polyacrylonitrile fiber, Polym. Degrad. Stab. 92 (2007) 1421-1432. 
[46]D. Bersani, P. P. Lottici, A. Montenero, Micro-Raman investigation of iron oxide films and powders produced by sol-gel syntheses. J. Raman Spectrosc. 30 (1999) 355-360.

[47]I. Cesar, K. Sivula, A. Kay, R. Zboril, M. Grätzel, Influence of feature size, film thickness, and silicon doping on the performance of nanostructured hematite photoanodes for solar water splitting. J. Phys. Chem. C 113 (2009) 772-782.

[48] M. A. Legodi, D. de Waal, The preparation of magnetite, goethite, hematite and maghemite of pigment quality from mill scale iron waste, Dyes and Pigments 74 (2007) 161-168.

[49] S. G. Leonardi, A. Mirzaei, A. Bonavita, S. Santangelo, P. Frontera, F. Pantò, P. L. Antonucci, G. Neri, A comparison of ethanol sensing properties of $\alpha$-iron oxide nanostructures prepared via sol-gel and electrospinning technics. Nanotechnology 27 (2016) 75502-75511.

[50]D. L. A. de Faria, S. V. Silva, M. T. de Oliveira, Raman microspectroscopy of some iron oxides and oxyhydroxides, J. Raman Spectrosc., 28 (1997) 873.

[51]C. T. Cherian, J. Sundaramurthy, M. Kalaivani, P. Ragupathy, P. S. Kumar, V. Thavasi, M. V. Reddy, C. H. Sow, S. G. Mhaisalkar, S. Ramakrishna, B. V. R. Chowdari, Electrospun $\alpha-\mathrm{Fe}_{2} \mathrm{O}_{3}$ nanorods as a stable, high capacity anode material for Li-ion batteries, J. Mater. Chem. 22 (2012) 12198.

[52] Y. El Mendili, F. Grasset, N. Randrianantoandro, N. Nerambourg, J. M. Greneche, J. F. Bardeau, Improvement of thermal stability of maghemite nanoparticles coated with oleic acid and oleylamine molecules: Investigations under laser irradiation, J. Phys. Chem. C 119 (2015) 10662.

[53] M. Zheng, H. Zhang, X. Gong, R. Xu, Y. Xiao, H. Dong, X. Liu, Y. Liu, A simple additive-free approach for the synthesis of uniform manganese monoxide nanorods with large specific surface area, Nanoscale Res. Lett. 8 (2013) 166.

[54] V. A. J. Silva, P. L. Andrade, M. P. C. Silva, A. Bustamante, D. L. De Los Santos Valladares, J. A. Aguiar, Synthesis and characterization of $\mathrm{Fe}_{3} \mathrm{O}_{4}$ nanoparticles coated with fucan polysaccharides, J. Magn. Magn. Mater. 343 (2013) 138-143.

[55]M. I. Dar, S. A. Shivashankar, Single crystalline magnetite, maghemite, and hematite nanoparticles with rich coercivity, RSC Advances 4 (2014) 4105.

[56] T. Radu, C. Iacovita, D. Benea, R. Turcu, X-ray photoelectron spectroscopic characterization of iron oxide nanoparticles, Appl. Surf. Sci. 405 (2017) 337-343.

[57]G. Bhanjana, N. Dilbaghi, N.K. Singhal, K.H.Kim, S. Kumar, Zinc oxide nanopillars as an electrocatalyst for direct redox sensing of cadmium J. Ind. Eng. Chem. 53 (2017) 192-200.

[58] S. A. Colorado, H. A. Colorado, Manufacturing of zinc oxide structures by thermal oxidation processes as scalable methods towards inexpensive electric generators, Ceramics International 43 (2017) 15846-15855.

[59]T. C. Damen, S. P. S. Porto, B. Tell, Raman effect in zinc oxide, Phys. Rev. 142 (1966) 570.

[60] M. Šćepanović, M. Grujić-Brojčin, K. Vojisavljević, S. Bernik, T. Srećković, Raman study of structural disorder in ZnO nanopowders, J. Raman Spectrosc. 41 (2010) 914-921.

[61]J. Hou, C. Cao, F. Idrees, X. Ma, Hierarchical porous nitrogen-doped carbon nanosheets derived from silk for ultrahigh-capacity battery anodes and supercapacitors, ACS Nano 9 (2015) 2556-2564.

[62]H. Liu, Y. Zhang, R. Li, X. Sun, S. Désilets, H. Abou-Rachid, M. Jaidann, L. S. Lussier, Structural and morphological control of aligned nitrogen-doped carbon nanotubes, Carbon 48 (2010) 1498-1570.

[63] Y. Shao, S. Zhang, M. H. Engelhard, G. Li, G. Shao, Y. Wang, J. Liu, I. A. Aksay, Y. Lin, Nitrogen-doped graphene and its electrochemical applications, J. Mater. Chem. 20 (2010) 7491-7496.

[64] Y. Qiua, J. Yu, T. Shi, X. Zhou, X. Bai, J. Y. Huanga, Nitrogen-doped ultrathin carbon nanofibers derived from electrospinning: Large-scale production, unique structure, and application as electrocatalysts for oxygen reduction, J. Power Sources 196 (2011) 9862-9867. 
[65]L. Qie, W. M. Chen, Z. H. Wang, Q. G. Shao, X. Li, L. X. Yuan, X. L. Hu, W. X. Zhang, Y. H. Huang, Nitrogen-doped porous carbon nanofiber webs as anodes for lithium ion batteries with a superhigh capacity and rate capability, Adv. Mater. 24 (2012) 2047-2050.

[66] G. S. Park, J. S. Lee, S. T. Kim, S. Park, J. Cho, Porous nitrogen doped carbon fiber with churros morphology derived from electrospun bicomponent polymer as highly efficient electrocatalyst for Zn-air batteries, J. Power Sources 243 (2013) 267-273.

[67]Z. Lin, Y. Liu, Y. Yao, O. J. Hildreth, Z. Li, K. Moon, C. Wong, Superior capacitance of functionalized graphene, J. Phys. Chem. C 115 (2011) 7120-7125.

[68]W. Yan, H. Fan, Y. Zhai, C. Yang, P. Ren, L. Huang, Low temperature solution-based synthesis of porous flower-like- $\mathrm{Fe}_{2} \mathrm{O}_{3}$ superstructures and their excellent gas-sensing properties, Sens. Actuators, B 160 (2011) 1372-1379.

[69] W.X. Jin, S.Y. Ma, Z.Z. Tie, X.H. Jiang, W.Q. Li, J. Luo, X.L. Xu, T.T. Wang, Hydrothermal synthesis of monodisperse porous cube, cake and spheroid-like- $\mathrm{Fe}_{2} \mathrm{O}_{3}$ particles and their high gas-sensing properties, Sens. Actuators, B 220 (2015) 243-254.

[70] T. Yamashita, P. Hayes, Analysis of XPS spectra of $\mathrm{Fe}^{2+}$ and $\mathrm{Fe}^{3+}$ ions in oxide materials, Appl. Surf. Sci. 254 (2008) 2441-2449.

[71]Zhang X., Li H., Wang S., Fan F.R.F., Bard A. J., Improvement of hematite as photocatalyst by doping with tantalum, J. Phys. Chem. C 118 (2014) 16842-16850.

[72]X. Tenga, H. Yang, Effects of surfactants and synthetic conditions on the sizes and selfassembly of monodisperse iron oxide nanoparticles, J. Mater. Chem. 14 (2004) 774-779.

[73]B. Sun, T. Shi, Z. Peng, W. Sheng, T. Jiang, G. Liao, Controlled fabrication of $\mathrm{Sn} / \mathrm{TiO}_{2}$ nanorods for photoelectrochemical water splitting, Nanoscale Res. Lett. 8 (2013) 462.

[74] J. Mičová, M. Buryi, D. Šimek, J. Drahokoupil, N. Neykova, Y. Y. Chang, Z. Remeš, O. PopGeorgievski, J. Svoboda, C. Im, Synthesis of zinc oxide nanostructures and comparison of their crystal quality, Appl. Surf. Sci., 461 (2018)190-195.

[75] W. Shi, H. Li, X. Cao, Z. Y. Leong, J. Zhang, T. Chen, H. Zhang, H. Y. Yang, Ultrahigh performance of novel capacitive deionization electrodes based on a three-dimensional graphene architecture with nanopores, Sci. Rep. 6 (2015) 18996 (9pp).

[76] V. Augustyn, P. Simon, B. Dunn, Pseudocapacitive oxide materials for high-rate electrochemical energy storage, Energy Environ. Sci. 7 (201) 1597-1614.

[77]M. T. Z. Myint, S. H. Al-Harthi, J. Dutta, Brackish water desalination by capacitive deionization using zinc oxide micro/nanostructures grafted on activated carbon cloth electrodes, Desalination 344 (2014) 236-242.

[78] C. D. Lokhande, D. P. Dubal, O. S. Joo, Metal oxide thin film based supercapacitors, Curr. Appl. Phys. 11 (2011) 255-270.

[79]J. Yu, L. Z. Gao, X. L. Li, C. Wu, L. L. Gao, C. M. Li, Porous carbons produced by the pyrolysis of green onion leaves and their capacitive behavior, New Carbon Mater. 31 (2016) 475-484.

[80] S. Ardizzone, G. Fregonara, S. Trasatti, "Inner" and "outer" active surface of $\mathrm{RuO}_{2}$ electrodes, Electrochim. Acta 35 (1990) 263-267.

[81] S. Patanè, C. Triolo, P. Cardiano, S. Lo Schiavo, Capacitive properties of the hydrophobic [2(methacryloyloxy) ethyl]-trimethyl ammonium nonafluoro-1-butanesulfonate poly(ionic liquid) thin film, Ionics 23 (2017) 1481-1487.

[82]G. Wang, L. Zhang, J. Zhang, A review of electrode materials for electrochemical supercapacitors, Chem. Soc. Rev. 41 (2012) 797-828.

[83] M. Noked, E. Avraham, A. Soffer, D. Aurbach, The rate-determining step of electroadsorption processes into nanoporous carbon electrodes related to water desalination, J. Phys. Chem. C 113 (2009) 21319-21327. 


\section{Figures captions}

Figure 1: (a-d) Morphology, (e-h) fibre diameter distributions and (i) elemental composition of the electrospun fibrous nanomaterials, as resulting from SEM/EDX analysis. The shown SEM images refer to samples (a) PMn, (b) PFe, (c) PTi and (d) PZn, whose morphology reminds of usnea florida lichens, wheat ears, sea sponges and nooddles, respectively. Histograms (e), (f), (g) and (h) respectively display the corresponding fibre diameter distributions. The shown elemental maps (i) refer to sample PMnG. Bar scale is $5 \mu \mathrm{m}$ in all SEM images.

Figure 2: Nitrogen sorption isotherms and pore size distributions (insets) of the investigated samples. The shown data refer to samples (a) PG, (b), PMn, (c) PMnG, (d) PFeG, (e) PFe and (f) PZn.

Figure 3: Results of XRD analysis on the electrospun fibrous nanomaterials. The shown XRD patterns refer to samples (a) Fe, (b), FeSi, (c) PMnG, (d) PFe, (e) PTi and (f) PZn. The spurious signal marked with a star in pattern (f) arises from the sample-holder.

Figure 4: (a) Results of Raman scattering measurements on the OFs and composite NC/OFs. The shown micro-Raman spectra refer to samples (a) Fe, (b), FeSi, (c) PMn, (d) PFe, (e) PTi and (f) PZn. (b) Micro-Raman spectrum of the GNCFs (sample PG). (c) Lower frequency region of the spectra of samples (a) PMnG, (b) PTi and (c) PZn, marked by a dashed grey square in plot (a).

Figure 5: (a-d) High-resolution photoelectron spectra of (a) Fe 2p, (b) Mn 2p, (c) Ti $2 p$ and (d) Zn $2 p$ core levels. In plot (a), the shown spectra refer to samples (a) Fe, (b) FeSi and (c) PFe; the inset shows the high-resolution photoelectron spectrum of Si $2 p$ core level in sample FeSi. In plot (b), the shown spectra refer to samples (a) PMn and (b) PMnG. Plot (c) refers to sample PTi; its inset displays the high-resolution photoelectron spectrum of $\mathrm{O} 1 \mathrm{~s}$ core level. Plot (d) refers to sample PZn.

Figure 6: CV curves of electrodes (a) PG, (b), PGmixFe, (c) PGmixFeSi, (d) PFeG, (e) PMnG, (f) PMn, (g) PFe, (h) PTi and (i) PZn, measured in a potential window of $-1-0.5 \mathrm{~V}$ at different scan rates.

Figure 7: Specific capacitance $\left(C_{\mathrm{S}}\right)$ of the investigated electrodes as a function of scan rate.

Figure 8: Specific capacitance $\left(C_{S}\right)$ of the investigated electrodes as a function of the overall amount of nitrogen and carbon-bonded oxygen on the surface of the active electrode material. The shown data refer to a scan rate of $5 \mathrm{mV} \mathrm{s}^{-1}$. A line is drawn to guide the eye.

Figure 9: Effective areal capacitance of some of the investigated electrodes as a function of the specific micro-pore-volume and the overall amount of nitrogen and carbon-bonded oxygen on the surface of the active electrode material. The shown data refer to a scan rate of $5 \mathrm{mV} \mathrm{s}^{-1}$.

Figure 10: Average $C_{\mathrm{S}}$ decrease-rate with scan-rate increase $\left(\Delta C_{\mathrm{S}} / \Delta v\right.$, with $\Delta v=95 \mathrm{mV} \mathrm{s} \mathrm{s}^{-1}$ scanrate variation, and $\Delta C_{\mathrm{S}}=C_{\mathrm{S}}(5)-C_{\mathrm{S}}(100)$ corresponding $C_{\mathrm{S}}$ change) as a function of the active material TMO-content. A line is drawn to guide the eye Data relative to samples $\mathrm{P}$ and $\mathrm{PG}$ are from ref. [13].

Figure 11: Nyquist plots of the investigated electrodes. Insets: mid-high frequency region of the plots. 

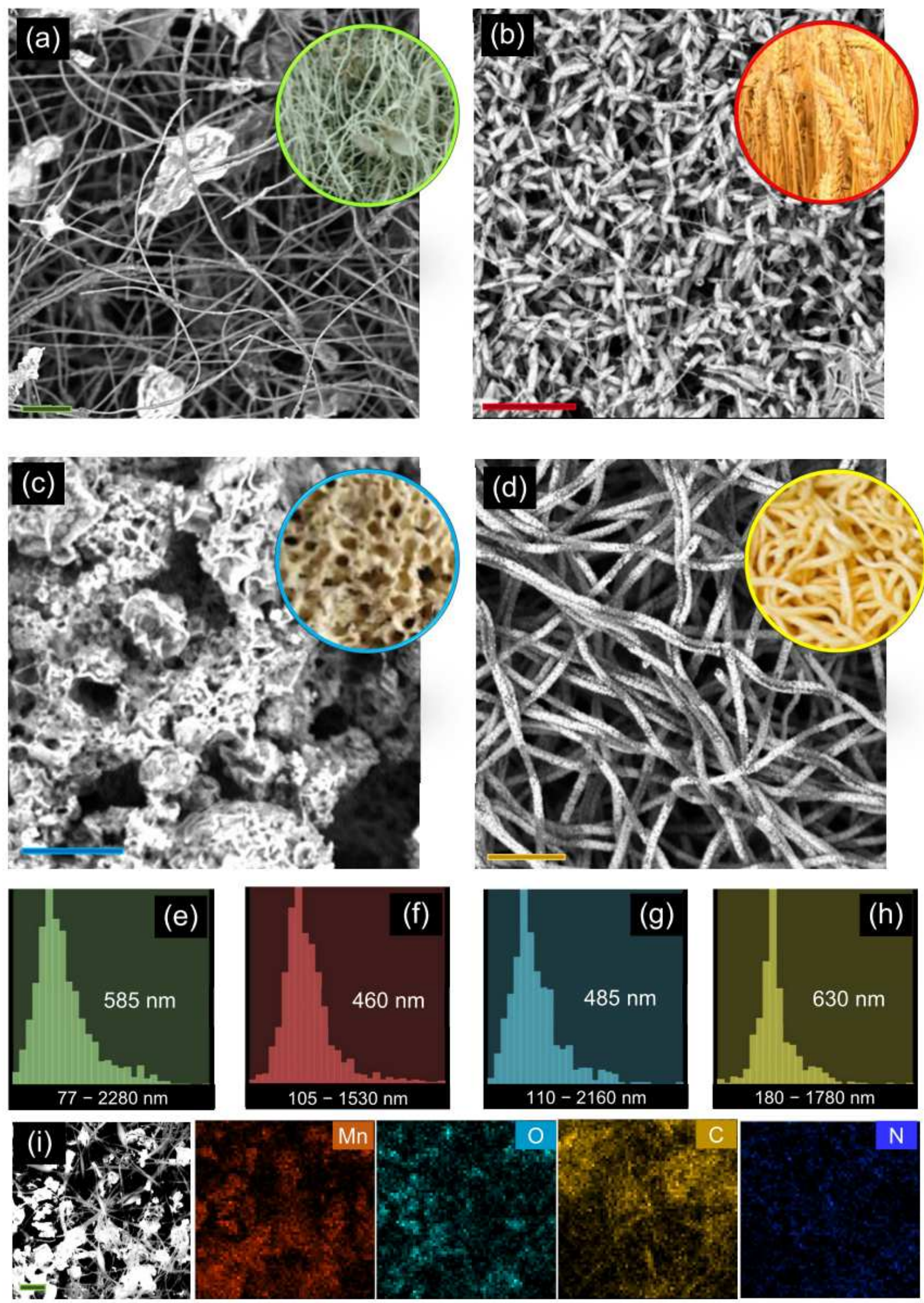

N

Figure 1 

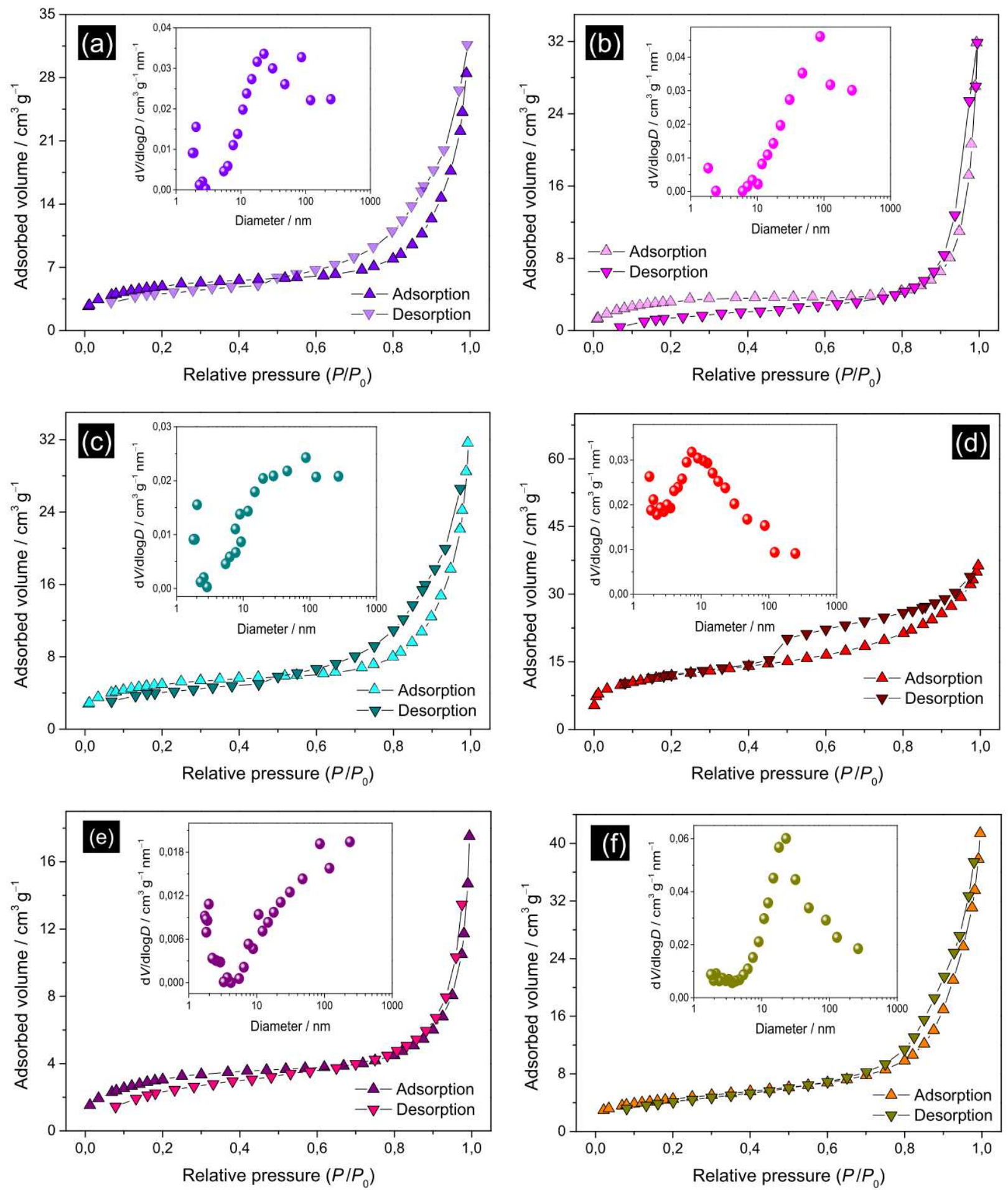

Figure 2 


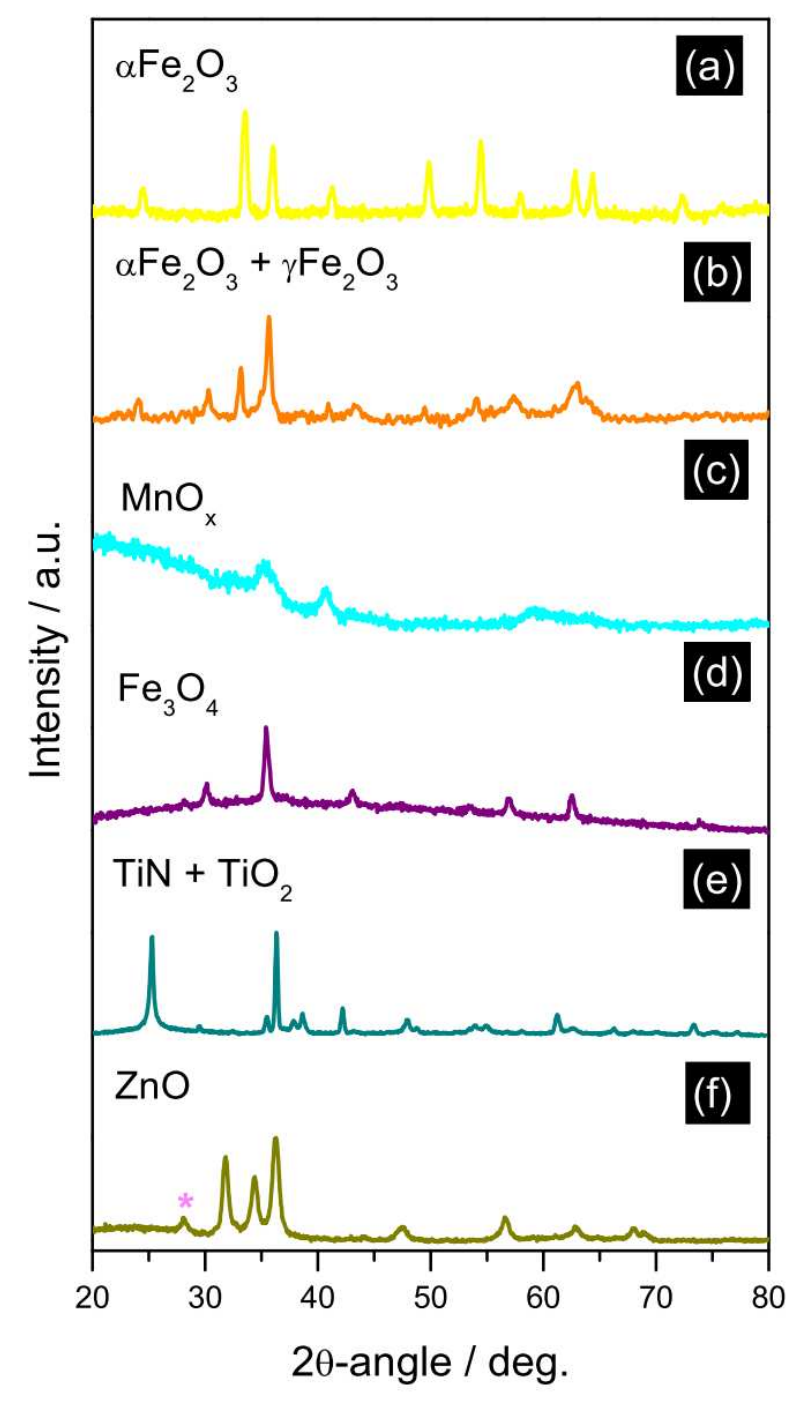

Figure 3 
(a)

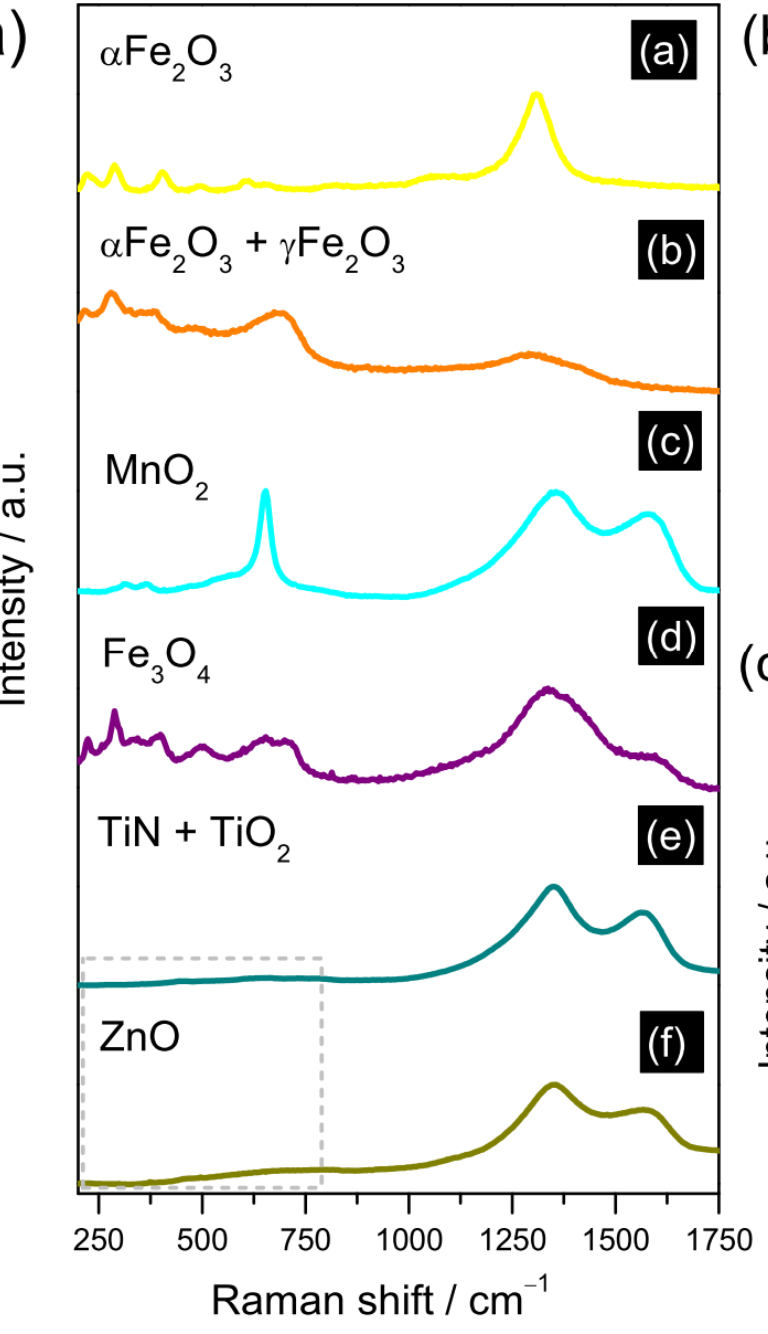

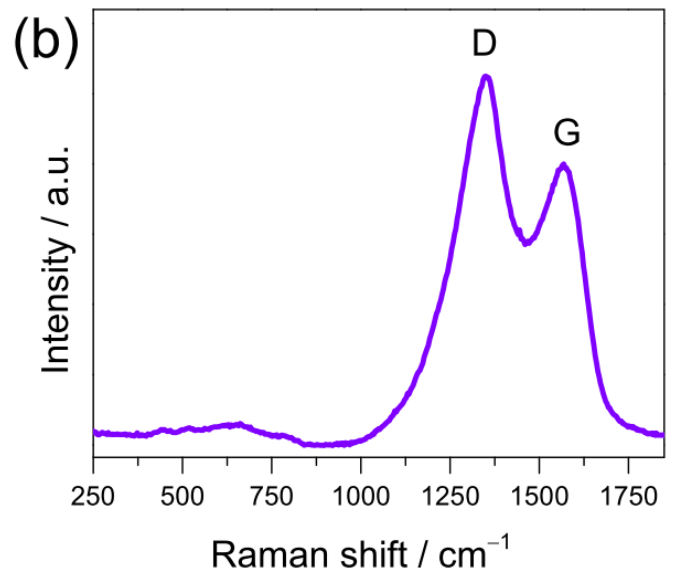

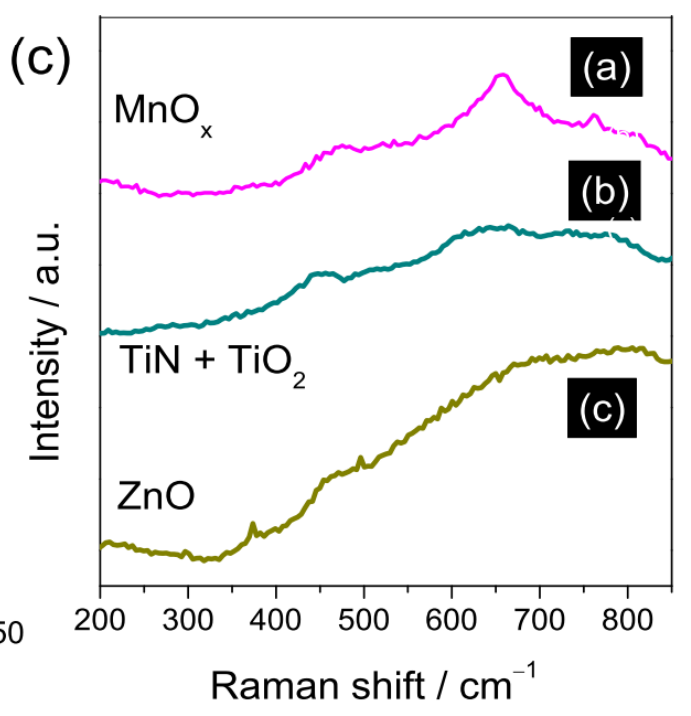

Figure 4 

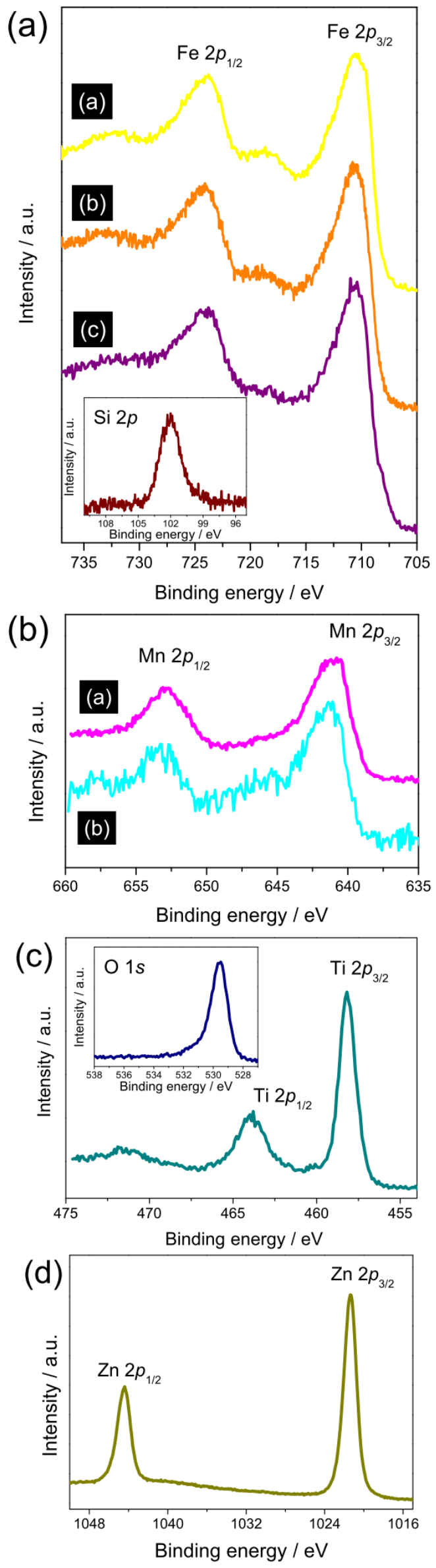

Figure 5 

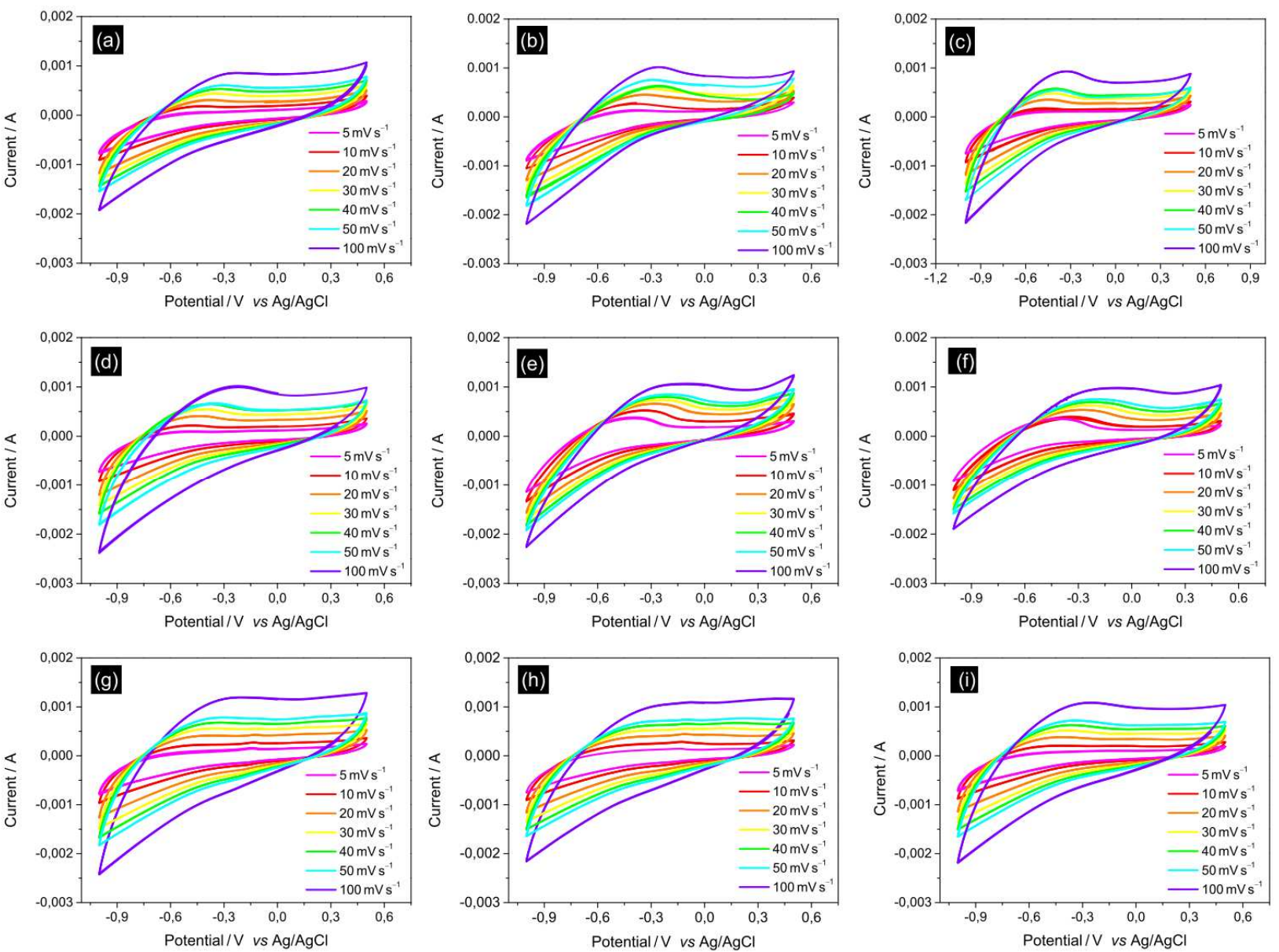

\section{Figure 6}

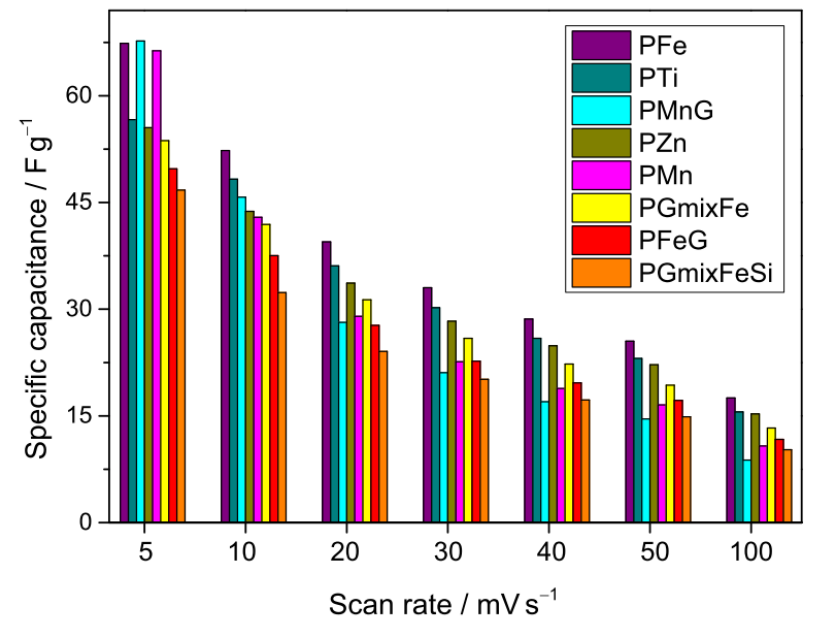

Figure 7 


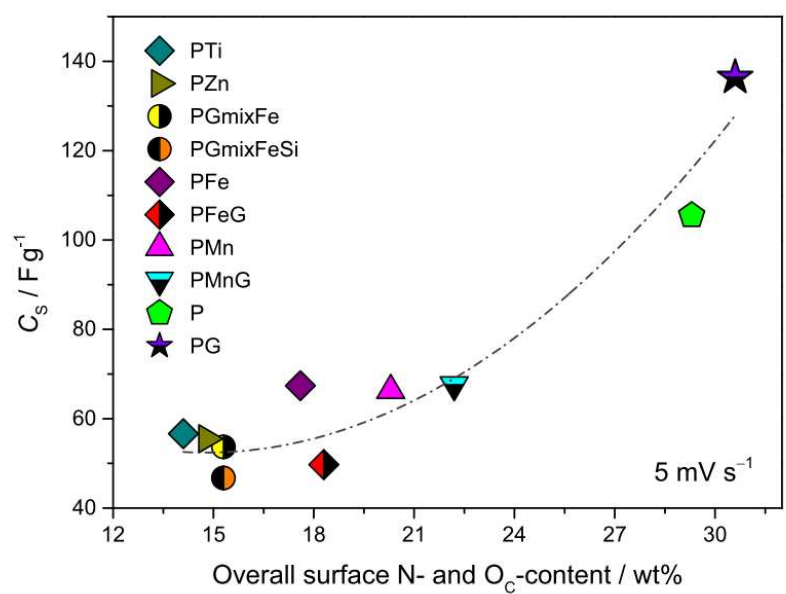

Figure 8

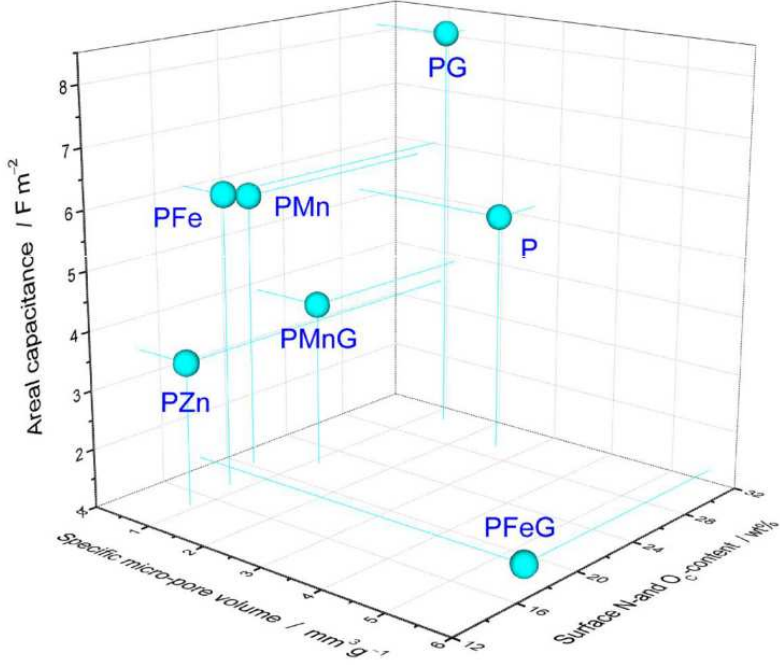

Figure 9 


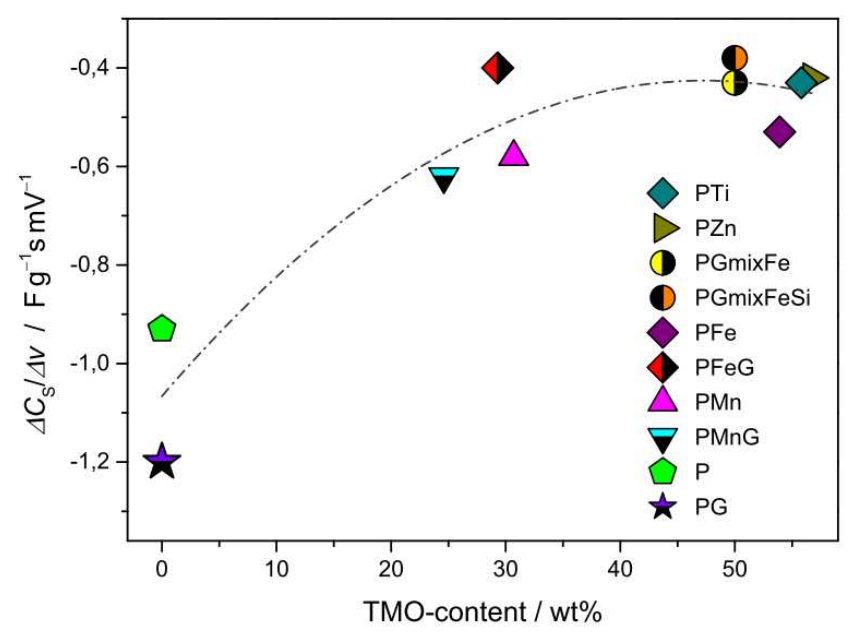

Figure 10 

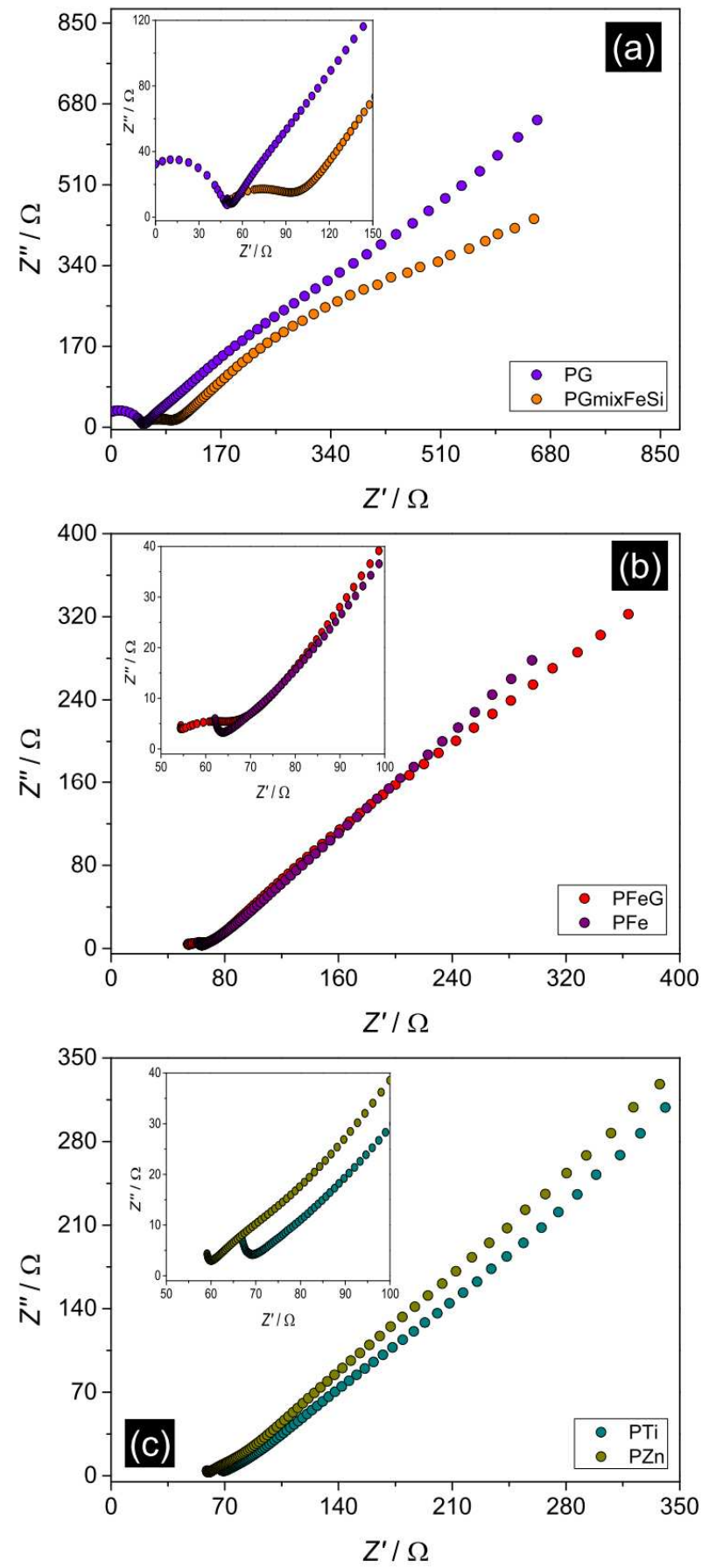

Figure 11 


\section{Tables}

Table 1: Sample codes, composition of the spinnable solution and thermal treatment conditions utilised to prepare the considered fibrous electrode nanomaterials. $w_{\mathrm{M}}, w_{\mathrm{D}}$ and $w_{\mathrm{GO}}$ denote the concentrations of metal, dopant and GO additive; the polymer concentration was fixed at $6.50 \mathrm{wt} \%$, whereas the solvent concentration varied in the range 89.75-93.17 $\mathrm{wt} \%$ to give the complement to $100 \mathrm{wt} \%$ (with precursor(s) and GO additive included). $T_{1}$ and $t_{1}$ stand for temperature and duration of the oxidative treatment in static air; $T_{2}$ and $t_{2}$ denote temperature and duration of the annealing treatment in inert atmosphere.

\begin{tabular}{|c|c|c|c|c|c|c|c|c|}
\hline $\begin{array}{l}\text { Material } \\
\text { code }\end{array}$ & $w_{\mathrm{M}} / \mathrm{wt} \%$ & $w_{\mathrm{D}} / \mathrm{wt} \%$ & $w_{\mathrm{GO}} / \mathrm{wt} \%$ & $T_{1} /{ }^{\circ} \mathrm{C}$ & $t_{1} / \mathrm{h}$ & $T_{2} /{ }^{\circ} \mathrm{C}$ & $t_{2} / \mathrm{h}$ & $\begin{array}{l}\text { Type of fibrous } \\
\text { material produced }\end{array}$ \\
\hline $\mathrm{Fe}$ & 2.50 & & & 600 & 2 & & & \multirow{2}{*}{ Oxide } \\
\hline $\mathrm{FeSi}$ & 2.25 & 0.25 & & 600 & 2 & & 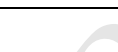 & \\
\hline PG & & & 0.33 & 280 & 3 & 500 & 3 & GN-carbon \\
\hline $\mathrm{PFeG}$ & 2.50 & & 0.33 & 280 & 3 & 500 & 3 & \multirow{6}{*}{ (G)N-carbon/oxide } \\
\hline PMnG & 2.50 & & 0.33 & 280 & 3 & 500 & 3 & \\
\hline PMn & 2.50 & & & 280 & 3 & 500 & 3 & \\
\hline $\mathrm{PFe}$ & 3.75 & & & 280 & 3 & 500 & 3 & \\
\hline PTi & 3.75 & & & 280 & 3 & 500 & 3 & \\
\hline PZn & 3.75 & & & 280 & 3 & 500 & 3 & \\
\hline
\end{tabular}

Table 2: Sample codes, type of fibrous nanomaterial produced and results of the SEM, BET and XRD analyses. $\Delta d_{\mathrm{F}}$ and $d_{\mathrm{F}}$ denote the fibre diameter range, as automatically calculated by the image analysis software, and centre value of the diameter distribution, respectively. $S_{\mathrm{BET}}$ and $V_{\mathrm{MP}}$ stand for specific surface area and specific micro-pore volume, respectively; $d_{\mathrm{P}}$ indicates the adsorption average pore size. $d_{\mathrm{G}}$ is the average size of the oxide crystallites, as estimated via the Scherrer equation from the most intense peak in the XRD pattern.

\begin{tabular}{|l|l|c|c|c|c|c|c|c|}
\hline Material code & $\begin{array}{l}\text { Fibrous material } \\
\text { produced }\end{array}$ & $\Delta d_{\mathrm{F}} / \mathrm{nm}$ & $d_{\mathrm{F}} / \mathrm{nm}$ & $S_{\mathrm{BET}} / \mathrm{m}^{2} \mathrm{~g}^{-1}$ & $V_{\mathrm{MP}} / \mathrm{mm}^{3} \mathrm{~g}^{-1}$ & $d_{\mathrm{P}} / \mathrm{nm}$ & $d_{\mathrm{G}} / \mathrm{nm}$ & Ref. \\
\hline $\mathrm{Fe}$ & $\alpha \mathrm{Fe}_{2} \mathrm{O}_{3}$ & $120-840$ & 230 & & & & 20 & {$[19]$} \\
\hline $\mathrm{FeSi}$ & $\alpha \mathrm{Fe}_{2} \mathrm{O}_{3+} \gamma \mathrm{Fe}_{2} \mathrm{O}_{3}$ & $70-1230$ & 330 & & & & 15 & {$[19]$} \\
\hline $\mathrm{PG}$ & $\mathrm{GN}-\mathrm{CFs}$ & $110-1070$ & 340 & 16.76 & 1.29 & 4.62 & $\mathrm{n} / \mathrm{a}$ & {$[13]$} \\
\hline $\mathrm{PFeG}$ & ${\mathrm{GN}-\mathrm{C} / \alpha \mathrm{Fe}_{2} \mathrm{O}_{3}}_{100-1460}$ & 440 & 41.96 & 5.58 & 4.74 & 14 & \\
\hline $\mathrm{PMnG}$ & $\mathrm{GN}-\mathrm{C} / \mathrm{MnO}_{\mathrm{x}}$ & $75-2170$ & 560 & 17.49 & 1.13 & 7.81 & 15 & \\
\hline $\mathrm{PMn}$ & $\mathrm{N}-\mathrm{C} / \mathrm{MnO}_{2}$ & $77-2280$ & 585 & 11.52 & 0.43 & 9.21 & 30 & \\
\hline $\mathrm{PFe}$ & $\mathrm{N}-\mathrm{C} / \mathrm{Fe}_{3} \mathrm{O}_{4}$ & $105-1530$ & 460 & 11.17 & 0.78 & 5.82 & 31 & \\
\hline $\mathrm{PTi}$ & $\mathrm{N}-\mathrm{C} / \mathrm{TiN} / \mathrm{TiO}_{2}$ & $110-2160$ & 485 & & & & $34^{\mathrm{a}} ; 25^{\mathrm{b}}$ & \\
\hline $\mathrm{PZn}$ & $\mathrm{N}-\mathrm{C} / \mathrm{ZnO}$ & $180-1780$ & 630 & 16.09 & 0.89 & 11.95 & 14 & \\
\hline
\end{tabular}

\footnotetext{
${ }^{\mathrm{a}} \mathrm{TiN} ;{ }^{\mathrm{b}} \mathrm{TiO}_{2}$
} 
Table 3: Surface composition of the samples, as inferred from the XPS analysis. TM and TMO denote transition metal and transition metal oxide, respectively. $\mathrm{O}_{\mathrm{T}}$ is oxygen present in the composite, while $\mathrm{O}_{\mathrm{C}}$ indicates the $\mathrm{C}$-bonded oxygen. The $\mathrm{O}_{\mathrm{C}} / \mathrm{C}$ atomic ratio of the carbonaceous component of the fibres is estimated by assuming that TMO is present in the composite fibres mainly in the form indicated in parentheses. Data relative to sample PG are from ref. [13].

\begin{tabular}{|l|c|c|c|c|c|c|c|c|c|}
\hline $\begin{array}{l}\text { Sample } \\
\text { code }\end{array}$ & C/at\% & $\mathrm{N} /$ at\% & $\mathrm{O}_{\mathrm{T}} / \mathrm{at} \%$ & $\mathrm{TM} / \mathrm{at} \%$ & $\mathrm{~N} / \mathrm{C}$ & $\mathrm{O}_{\mathrm{C}} / \mathrm{C}$ & $\mathrm{N} / \mathrm{wt} \%$ & $\mathrm{O}_{\mathrm{C}} / \mathrm{wt} \%$ & $\mathrm{TMO} / \mathrm{wt} \%$ \\
\hline PG & 73.5 & 17.5 & 9.0 & 0.0 & 0.238 & 0.122 & 19.3 & 11.3 & 0.0 \\
\hline PFeG & 66.7 & 14.9 & 12.8 & 5.6 & 0.223 & 0.066 & 13.7 & 4.6 & $\left(\mathrm{Fe}_{2} \mathrm{O}_{3}\right) 29.3$ \\
\hline PMnG & 67.2 & 16.1 & 11.5 & 5.2 & 0.240 & $0.094^{\mathrm{a}}$ & 15.0 & $7.2^{\mathrm{a}}$ & $(\mathrm{MnO}) 24.6$ \\
\hline PMn & 62.5 & 15.6 & 16.5 & 5.4 & 0.250 & 0.093 & 14.3 & 6.0 & $\left(\mathrm{MnO}_{2}\right) 30.7$ \\
\hline PFe & 45.9 & 10.1 & 30.5 & 13.5 & 0.220 & 0.272 & 7.3 & 10.3 & $\left(\mathrm{Fe}_{3} \mathrm{O}_{4}\right) 53.9$ \\
\hline PTi & 45.5 & 9.2 & 32.8 & 12.5 & $0.203^{\mathrm{a}}$ & 0.171 & $7.2^{\mathrm{a}}$ & 6.9 & $\left(\mathrm{TiO}_{2}\right) 55.8$ \\
\hline PZn & 44.5 & 9.6 & 21.9 & 13.0 & 0.216 & 0.198 & 7.2 & 7.6 & $(\mathrm{ZnO}) 56.7$ \\
\hline
\end{tabular}

${ }^{\mathrm{a}}$ The value might be overestimated owing to the presence of a secondary phase.

Table 4: Codes of the working electrodes and fibrous active nanomaterials utilised for their preparation (the nanomaterial codes are reported in brackets).

\begin{tabular}{|ll|}
\hline Electrode code & Active fibrous nanomaterial produced (and relative codes) \\
\hline PG (reference) & GNCFs $(\mathrm{PG})$ \\
\hline PGmixFe & $1: 1$ mixture of GN-CFs $(\mathrm{PG})$ and $\alpha \mathrm{Fe}_{2} \mathrm{O}(\mathrm{Fe})$ \\
\hline PGmixFeSi & $1: 1$ mixture of GN-CFs $(\mathrm{PG})$ and $\alpha \mathrm{Fe}_{2} \mathrm{O}_{3+} \gamma \mathrm{Fe}_{2} \mathrm{O}_{3}(\mathrm{FeSi})$ \\
\hline $\mathrm{PFeG}$ & $\mathrm{GN}-\mathrm{C} / \alpha \mathrm{Fe}_{2} \mathrm{O}_{3}(\mathrm{PFeG})$ \\
\hline $\mathrm{PMnG}$ & $\mathrm{GN}-\mathrm{C} / \mathrm{MnO}_{\mathrm{x}}(\mathrm{PMnG})$ \\
\hline $\mathrm{PMn}$ & $\mathrm{N}-\mathrm{C} / \mathrm{MnO}_{2}(\mathrm{PMn})$ \\
\hline $\mathrm{PFe}$ & $\mathrm{N}-\mathrm{C} / \mathrm{Fe}_{3} \mathrm{O}_{4}(\mathrm{PFe})$ \\
\hline $\mathrm{PTi}$ & $\mathrm{N}-\mathrm{C} / \mathrm{TiN} / \mathrm{TiO} \mathrm{O}_{2}(\mathrm{PTi})$ \\
\hline $\mathrm{PZn}$ & $\mathrm{N}-\mathrm{C} / \mathrm{ZnO}(\mathrm{PZn})$ \\
\hline
\end{tabular}

